\title{
Reduced order modelling and predictive control of multivariable nonlinear process
}

\author{
ANUJ ABRAHAM ${ }^{1, *}, \mathrm{~N} \mathrm{PAPPA}^{2}$, DANIEL HONC $^{3}$ and RAHUL SHARMA ${ }^{4}$ \\ ${ }^{1}$ Department of Applied Electronics \& Instrumentation, Rajagiri School of Engineering \& Technology, APJ \\ Abdul Kalam Technological University, Kerala, India \\ ${ }^{2}$ Department of Instrumentation Engineering, Madras Institute of Technology Campus, Anna University, \\ Chennai, India \\ ${ }^{3}$ Department of Process Control, Faculty of Electrical Engineering and Informatics, University of Pardubice, \\ Pardubice, Czech Republic \\ ${ }^{4}$ Department of Electrical and Electronics Engineering, Amrita School of Engineering, Amrita University, \\ Coimbatore, India \\ e-mail: anuj1986aei@gmail.com; npappa@ rediffmail.com; daniel.honc@upce.cz; \\ k_rahulsharma@cb.amrita.edu
}

MS received 26 October 2015; revised 26 May 2017; accepted 17 October 2017; published online 16 March 2018

\begin{abstract}
In this paper, an efficient model-predictive control strategy that can be applied to complex multivariable process is presented. A reduced order generalized predictive algorithm is proposed for online applications with reduction in complexity and time elapsed. The complex multivariable process considered in this work is a binary distillation column. The reduced order model is developed with a recently proposed hybrid algorithm known as Clustering Dominant Pole Algorithm and is able to compute the full set of dominant poles and their cluster centre efficiently. The controller calculates the optimal control action based on the future reference signals, current state and constraints on manipulated and controlled variables for a high-order dynamic simulated model of nonlinear multivariable binary distillation column process. The predictive control algorithm uses controlled auto-regressive integrated moving average model. The performance of constraint generalized predictive control scheme is found to be superior to that of the conventional PID controller in terms of overshoot, settling time and performance indices, mainly ISE, IAE and MSE.
\end{abstract}

Keywords. Predictive control; distillation column; reduced order model; dominant pole; clustering.

\section{Introduction}

Model-predictive control (MPC) is very frequently used and an important advanced control technique for difficult multivariable control problems with constrained parameters. Predictive algorithms are very popular techniques to solve optimal control problems in the discrete-time domain and suitable for non-minimum phase systems, process with delays, unstable systems and multivariable processes. It is designed to handle complex, constrained, high-dimensional processes with different numbers of controlled and manipulated variables even for non-linear processes. The importance of predictive algorithms in industrial applications includes explicit use of a dynamical process model for controlled variable prediction at a future time horizon and usage of an online optimization tool, which will generate optimal control actions required at every time instance by

*For correspondence minimizing an objective function based on predictions as the key features [1].

The various predictive algorithms differ amongst themselves in the model used to represent the process, the cost function to be minimized and optimization method. A conventional controller observes only the current and remembers the past process variables, whereas a predictive controller observes the current and also the future process variables and remembers the past variables [2]. It has features of optimal control, stochastic control, deterministic control, multivariable control, control of processes with dead time and future references when available. The main advantage of predictive algorithms is the receding strategy - at every sample time instant, the horizon is shifted towards the future and the whole procedure is repeated again [3].

The various predictive algorithms differ amongst themselves in the model used to represent the process and the cost function to be minimized [4]. In this paper, the Controlled Auto-Regressive Integrated Moving Average (CARIMA) model is considered and the key advantage of 
using Generalized Predictive Control (GPC) is that it utilizes input-output model without a requirement that state measurement is needed $[5,6]$. The process model is used for the plant behaviour prediction and a receding horizon concept is applied to introduce the feedback.

With the increase in computational power, the MPC is not only limited to slow dynamics processes, where dynamical optimization is easily possible, but also there are new applications for faster systems; for example, MPC control techniques for trajectory tracking of mobile robots.

Specific eigenvectors and eigenvalues of the state matrix relate the dominant modes to corresponding dominant poles of the system transfer function. An eigenvalue method is required that computes the most dominant poles and corresponding modes [7, 8]. The Dominant Pole Algorithm (DPA) works only for stable systems as reported by Martins et al [9]. The recently proposed hybrid algorithm [10] combines the clustering method and DPA method. The Clustering Dominant Pole Algorithm (CDPA) method efficiently computes the poles that are more dominant in the system and retains the original characteristic behaviour [11]. The denominator polynomial of the reduced order model with respect to original model is determined by forming the clusters of the dominant poles and the coefficients of numerator polynomial with respect to original model are obtained by using the factor division algorithm. Comparative performance evaluations are analysed for both conventional PID and GPC as a class of MPC for firstprinciple model, linearized full order and reduced order models of a binary distillation column process.

\section{Process description}

Distillation column is the most commonly used separation method in the petroleum and chemical industries for purification of final products [12]. The design and efficient control of distillation column is a challenging task due to high non-linearity and dynamic behaviour. Binary distillation column consists of a vertical column, where plates or trays are used to increase the component separations. The portion of the column below the feed tray is called the stripping section and the trays above the feed tray are called rectification section. A condenser is used to cool or condense distillate vapour and the re-boiler is a heat exchanger, used to provide heat for the necessary vaporization from the bottom of the column. Condensed vapour is collected in a reflux drum and required amount of it is used as a reflux $[13,14]$. The vertical column is designed for 14 trays plus condenser and re-boiler.

\subsection{Mathematical modelling}

2.1a Assumptions: The various assumptions considered for the distillation column modelling are given here: a) The relative volatility $\alpha$ is constant throughout the column. This means the vapor-liquid equilibrium relationship can be expressed by Eq. (10).

b) The overhead vapour is totally condensed in a condenser.

c) The liquid holdups on each tray, condenser and the reboiler are constant and perfectly mixed.

d) The holdup of vapour is negligible throughout the system.

e) The molar flow rates of the vapour and liquid through the stripping and rectifying sections are constant.

The vertical column is designed for 14 trays plus condenser and re-boiler and is numbered from the bottom; 1 represents the re-boiler stage, $m=2-7$ for the trays below the feed tray, $f=8$ for the tray immediately below the feed tray, $f=9$ for the tray immediately above the feed tray, $n=10-14$ for the remaining trays above the feed tray, $N=15$ for the tray below the condenser and $N+1=16$ for the condenser stage.

2.1b Non-linear first-principle model: The plant nominal capacity is $130,000 \mathrm{t}$ of raw condensate per year based on 24 operating hours per day and 350 working days per year [12]. The plant equipment is specified with a design margin of $10 \%$ above the nominal capacity and turndown ratio of $50 \%$. Hence, the raw condensate feed rate for the plant is determined as follows:

$$
\begin{aligned}
\text { feed } & =130,000 \mathrm{t} /((24 h) \times(350 \text { working days })) \\
& =15.47619 \mathrm{t} / \mathrm{h}
\end{aligned}
$$

- the feed mass rate of the plant: $F_{\text {mass }}=15.47619(\mathrm{t} / \mathrm{h})$;

- the gas percentage in the feed flow: $c_{\mathrm{F}}=38 \%$;

- The internal vapour flow $V_{\mathrm{F}}$ is selected by the empirical relation $V_{\mathrm{F}}=28 \%$;

- The feed stream $\left(\mathrm{m}^{3} / \mathrm{h}\right)$ with the density $\rho_{\mathrm{F}}=0.670$ $\mathrm{t} / \mathrm{m}^{3}$ is calculated as follows:

$$
F=F_{\text {mass }} / \rho_{\mathrm{F}}=15.47619 / 0.670=23.0988 \mathrm{~m}^{3} / \mathrm{h}
$$

Composition $X_{\mathrm{F}}$ in the liquid and $Y_{\mathrm{F}}$ in the vapour phase of the feed are obtained by solving the flash equations

$$
\begin{gathered}
F c_{\mathrm{F}}=L_{\mathrm{F}} X_{\mathrm{F}}+V_{\mathrm{F}} Y_{\mathrm{F}}, \\
Y_{\mathrm{F}}=\alpha X_{\mathrm{F}} /\left(1+(\alpha-1) X_{\mathrm{F}}\right) .
\end{gathered}
$$

Solving the flash equation with the relative volatility $\alpha=5.68$, using Eqs. (1) and (2) gives $X_{\mathrm{F}}=0.26095$ and $Y_{\mathrm{F}}=0.66728$. Aschematic diagram of the multivariable nonlinear process considered is shown in figure 1.

The ordinary differential equation (ODE) representing the mathematical model of benchmark multivariable binary 


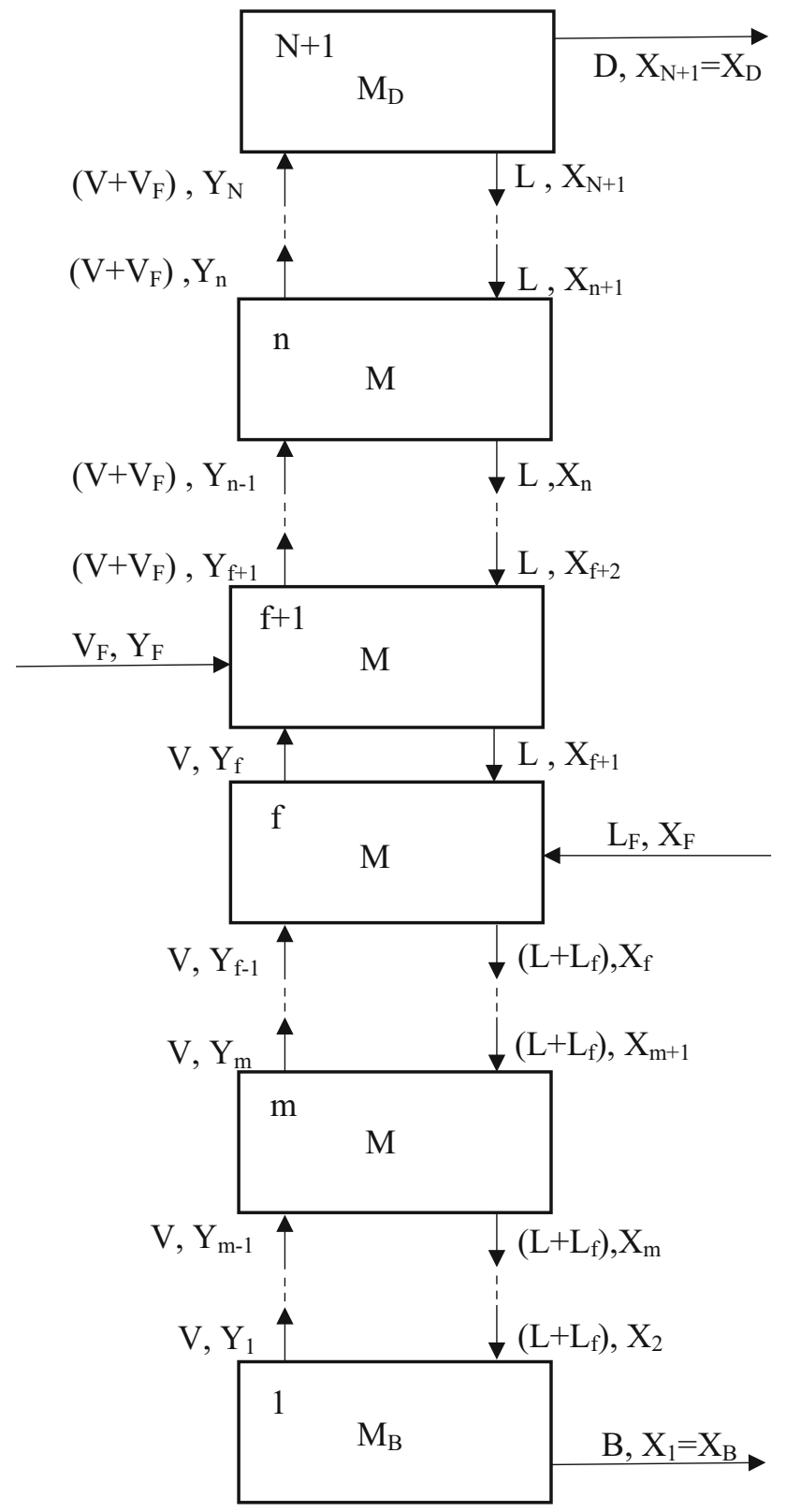

Figure 1. Schematic diagram of binary distillation column process. distillation column [12, 13, 15] and simplified expressions are given in Eqs. (4)-(13).

Condenser $(N+1=16)$ :

$$
\mathrm{M}_{\mathrm{D}} \dot{\mathrm{X}}_{\mathrm{D}}=\left(\mathrm{V}+\mathrm{V}_{\mathrm{F}}\right) \mathrm{Y}_{\mathrm{N}}-\mathrm{LX}_{\mathrm{N}+1}-\mathrm{DX}_{\mathrm{D}}
$$

Tray $n(n=10$ to $N=15)$ :

$$
\mathrm{M} \dot{\mathrm{X}}_{\mathrm{n}}=\left(\mathrm{V}+\mathrm{V}_{\mathrm{F}}\right)\left(\mathrm{Y}_{\mathrm{n}-1}-\mathrm{Y}_{\mathrm{n}}\right)+\mathrm{L}\left(\mathrm{X}_{\mathrm{n}+1}-\mathrm{X}_{\mathrm{n}}\right) \text {. }
$$

Tray above the feed flow $(f+1=9)$ :

$$
\begin{aligned}
\mathrm{M} \dot{\mathrm{X}}_{\mathrm{f}+1}= & \mathrm{V}\left(\mathrm{Y}_{\mathrm{f}}-\mathrm{Y}_{\mathrm{f}+1}\right)+\mathrm{L}\left(\mathrm{X}_{\mathrm{f}+2}-\mathrm{X}_{\mathrm{f}+1}\right)+\mathrm{V}_{\mathrm{F}}\left(\mathrm{Y}_{\mathrm{F}}\right. \\
& \left.-\mathrm{Y}_{\mathrm{f}+1}\right) .
\end{aligned}
$$

Tray below the feed flow $(f=8)$ :

$$
M \dot{X}_{f}=V\left(Y_{f-1}-Y_{f}\right)+L\left(X_{f+1}-X_{f}\right)+L_{F}\left(X_{F}-X_{f}\right) .
$$

Tray $m(m=2-7)$ :

$$
\mathrm{M} \dot{\mathrm{X}}_{\mathrm{m}}=\mathrm{V}\left(\mathrm{Y}_{\mathrm{m}-1}-\mathrm{Y}_{\mathrm{m}}\right)+\left(\mathrm{L}+\mathrm{L}_{\mathrm{F}}\right)\left(\mathrm{X}_{\mathrm{m}+1}-\mathrm{X}_{\mathrm{m}}\right) .
$$

\section{Re-boiler (Tray 1):}

$$
\begin{gathered}
\mathrm{M}_{\mathrm{B}} \dot{\mathrm{X}}_{\mathrm{B}}=\left(\mathrm{L}+\mathrm{L}_{\mathrm{F}}\right) \mathrm{X}_{2}-\mathrm{VY}_{1}-\mathrm{BX}_{\mathrm{B}}, \\
\mathrm{Y}_{\mathrm{n}}=\frac{\alpha \mathrm{X}_{\mathrm{n}}}{1+(\alpha-1) \mathrm{X}_{\mathrm{n}}}, \\
\mathrm{D}+\mathrm{B}=\mathrm{V}_{\mathrm{F}}+\mathrm{L}_{\mathrm{F}}, \\
\mathrm{V}+\mathrm{V}_{\mathrm{F}}=\mathrm{D}+\mathrm{L}, \\
\mathrm{L}+\mathrm{L}_{\mathrm{F}}=\mathrm{B}+\mathrm{V} .
\end{gathered}
$$

The various stream data and nominal values for process parameters used in the mathematical modelling of binary distillation column process are listed in tables 1 and 2, respectively.

\subsection{Linearized model in deviation form}

To obtain the linearized model in transfer function model form, the first-principle equations are linearized and converted into deviation form [16]. The linearization is carried

Table 1. Stream data for distillation column process.

\begin{tabular}{lcccccrr}
\hline Stream & Formula & $\%$ & Volume $\left(\mathrm{m}^{3} / \mathrm{h}\right)$ & Density $\left(\mathrm{t} / \mathrm{m}^{3}\right)$ & Mass $(\mathrm{t} / \mathrm{h})$ & Molar $(\mathrm{kg} / \mathrm{kmol})$ & Molar flow $(\mathrm{kmol} / \mathrm{h})$ \\
\hline Vapour rate in feed $V_{\mathrm{F}}$ & $c_{\mathrm{F}+4}$ & 42 & 9.7015 & 0.591 & 5.7336 & 58.2 & 98.5152 \\
Liquid rate in feed $L_{\mathrm{F}}$ & $100-c_{\mathrm{F}}$ & 58 & 13.3973 & 0.726 & 9.7264 & 93.3 & 104.2491 \\
Internal vapour rate $V$ & $V_{\mathrm{f}}$ & 28 & 6.4677 & 0.598 & 3.8677 & 58.3 & 66.3407 \\
Internal liquid rate $L$ & $V_{\mathrm{f}+4}$ & 32 & 7.3916 & 0.615 & 4.5458 & 60.1 & 75.6380 \\
Distillate flow rate $D$ & $c_{\mathrm{F}}$ & 38 & 8.7775 & 0.576 & 5.0554 & 54.5 & 92.7597 \\
Bottom flow rate $B$ & $100-c_{\mathrm{F}}$ & 62 & 14.3213 & 0.727 & 10.405 & 93.8 & 110.9235
\end{tabular}


Table 2. Nominal values for process parameters of distillation column process.

\begin{tabular}{lccc}
\hline Variable & Stream & Molar flow & Unit \\
\hline$M_{B}$ & Liquid holdup in the column base & 31.11 & $\mathrm{kmol}$ \\
$M$ & Liquid holdup on a tray & 5.8 & $\mathrm{kmol}$ \\
$M_{D}$ & Liquid holdup in the reflux drum & 13.07 & $\mathrm{kmol}$ \\
\hline
\end{tabular}

out for specific molar flow $L$ and $V$ concentration distributions in liquid and vapour phase at different column trays and the condenser. The full order linearized model in state space representation obtained from the first-principle equations in terms of deviation variables is given by the equation

$$
\begin{aligned}
& \dot{X}(\mathrm{t})=\mathbf{A} \cdot \mathrm{X}(\mathrm{t})+\mathbf{B} \cdot \mathrm{u}(\mathrm{t}) \\
& \mathrm{Y}(\mathrm{t})=\mathbf{C} \cdot \mathrm{X}(\mathrm{t})+\mathbf{D} \cdot \mathrm{u}(\mathrm{t})
\end{aligned}
$$

where

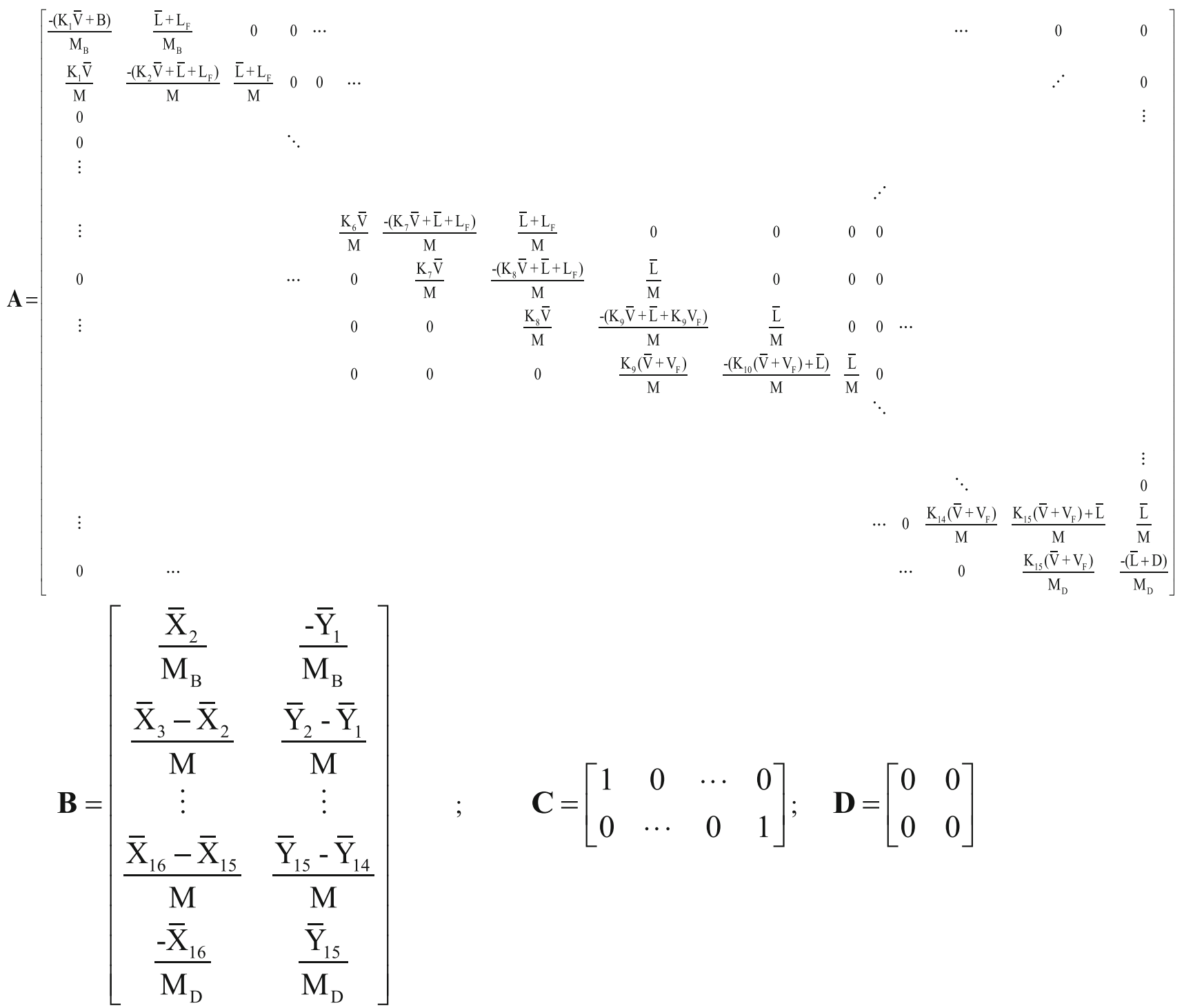

$$
\begin{gathered}
\mathrm{u}(\mathrm{t})=\left[\begin{array}{c}
\Delta \mathrm{L} \\
\Delta \mathrm{V}
\end{array}\right], \quad \mathrm{Y}(t)=\left[\begin{array}{c}
\Delta \mathrm{X}_{\mathrm{B}} \\
\Delta \mathrm{X}_{\mathrm{D}}
\end{array}\right] \\
\mathrm{X}(\mathrm{t})=\left[\begin{array}{c}
\mathrm{X}_{1}-\overline{\mathrm{X}}_{1} \\
\mathrm{X}_{2}-\overline{\mathrm{X}}_{2} \\
\vdots \\
\mathrm{X}_{15}-\overline{\mathrm{X}}_{15} \\
\mathrm{X}_{16}-\overline{\mathrm{X}}_{16}
\end{array}\right]=\left[\begin{array}{c}
\Delta \mathrm{X}_{1} \\
\Delta \mathrm{X}_{2} \\
\vdots \\
\Delta \mathrm{X}_{15} \\
\Delta \mathrm{X}_{16}
\end{array}\right] \\
\mathrm{Y}\left(\overline{\mathrm{X}}_{\mathrm{n}}\right)=\frac{\alpha\left(\mathrm{X}_{\mathrm{n}}-\overline{\mathrm{X}}_{\mathrm{n}}\right)}{1+(\alpha-1) \overline{\mathrm{X}}_{\mathrm{n}}+\frac{\mathrm{K}_{\mathrm{n}}=\frac{\mathrm{df}}{\mathrm{d} \mathrm{X}_{\mathrm{n}}}, \text { at }}{\left(1+\overline{\mathrm{X}}_{\mathrm{n}}\right)^{2}}} \\
\mathrm{X}_{\mathrm{n}}=\overline{\mathrm{X}}_{\mathrm{n}} \Rightarrow \quad \mathrm{K}_{\mathrm{n}}=\frac{\alpha}{\left(1+(\alpha-1) \overline{\mathrm{X}}_{\mathrm{n}}\right)^{2}}
\end{gathered}
$$

The $\mathbf{A}, \mathbf{B}, \mathbf{C}, \mathbf{D}$ matrices of the linearized model are given as follows: 
Substituting the values $\bar{L}=L=75.6380$,

$\bar{V}=V=66.3407, \quad L_{\mathrm{F}}=104.2491, \quad V_{\mathrm{F}}=98.5152$,

$D=92.7597, B=110.9235, M_{D}=13.07, M_{B}=31.11$,

$M=5.8, \alpha=5.68, X_{\mathrm{F}}=0.2609$ and $Y_{\mathrm{F}}=0.66728$ the

state space matrices $\mathbf{A}-\mathbf{C}$ are obtained and steady-state values of composition on each trays are listed in table 3 .

\section{Full order transfer function matrix.}

From input 1 to output...

$$
\begin{array}{r}
0.0025 s^{15}+1.48 s^{14}+390.8 s^{13}+6.096 \mathrm{e} 04 s^{12}+6.261 \mathrm{e} 06 s^{11}+4.469 \mathrm{e} 08 s^{10} \\
+2.281 \mathrm{e} 10 s^{9}+8.436 \mathrm{e} 11 s^{8}+2.266 \mathrm{e} 13 s^{7}+4.388 \mathrm{e} 14 s^{6}+6.022 \mathrm{e} 15 s^{5}+5.685 \mathrm{e} 16 s^{4} \\
+3.516 \mathrm{e} 17 s^{3}+1.31 \mathrm{e} 18 s^{2}+2.476 \mathrm{e} 18 s+1.096 \mathrm{e} 18 \\
\hline s^{16}+580.3 s^{15}+1.504 \mathrm{e} 05 s^{14}+2.304 \mathrm{e} 07 s^{13}+2.327 \mathrm{e} 09 s^{12}+1.635 \mathrm{e} 11 s^{11} \\
+8.233 \mathrm{e} 12 s^{10}+3.012 \mathrm{e} 14 s^{9}+8.036 \mathrm{e} 15 s^{8}+1.555 \mathrm{e} 17 s^{7}+2.151 \mathrm{e} 18 s^{6}+2.072 \mathrm{e} 19 s^{5} \\
+1.333 \mathrm{e} 20 s^{4}+5.334 \mathrm{e} 20 s^{3}+1.171 \mathrm{e} 21 s^{2}+1.089 \mathrm{e} 21 s+2.784 \mathrm{e} 20
\end{array}
$$

From input 2 to output...

$$
\begin{aligned}
& -0.005 s^{15}-3.002 s^{14}-804.3 s^{13}-1.273 \mathrm{e} 05 s^{12}-1.326 \mathrm{e} 07 s^{11}-9.602 \mathrm{e} 08 s^{10} \\
& -4.974 \mathrm{e} 10 s^{9}-1.867 \mathrm{e} 12 s^{8}-5.093 \mathrm{e} 13 s^{7}-1.002 \mathrm{e} 15 s^{6}-1.395 \mathrm{e} 16 s^{5}-1.333 \mathrm{e} 17 s^{4} \\
& 1: \frac{-8.279 \mathrm{e} 17 s^{3}-3.032 \mathrm{e} 18 s^{2}-5.293 \mathrm{e} 18 s-1.657 \mathrm{e} 18}{s^{16}+580.3 s^{15}+1.504 \mathrm{e} 05 s^{14}+2.304 \mathrm{e} 07 s^{13}+2.327 \mathrm{e} 09 s^{12}+1.635 \mathrm{e} 11 s^{11}+8.233 \mathrm{e} 12 s^{10}} \\
& +3.012 \mathrm{e} 14 s^{9}+8.036 \mathrm{e} 15 s^{8}+1.555 \mathrm{e} 17 s^{7}+2.151 \mathrm{e} 18 s^{6}+2.072 \mathrm{e} 19 s^{5}+1.333 \mathrm{e} 20 s^{4} \\
& +5.334 \mathrm{e} 20 s^{3}+1.171 \mathrm{e} 21 s^{2}+1.089 \mathrm{e} 21 s+2.784 \mathrm{e} 20 \\
& 0.0754 s^{15}+42.78 s^{14}+1.079 \mathrm{e} 04 s^{13}+1.598 \mathrm{e} 06 s^{12}+1.55 \mathrm{e} 08 s^{11}+1.036 \mathrm{e} 10 s^{10} \\
& +4.902 \mathrm{e} 11 s^{9}+1.659 \mathrm{e} 13 s^{8}+4.012 \mathrm{e} 14 s^{7}+6.843 \mathrm{e} 15 s^{6}+8.022 \mathrm{e} 16 s^{5}+6.189 \mathrm{e} 17 s^{4} \\
& 2: \frac{+2.918 \mathrm{e} 18 s^{3}+7.352 \mathrm{e} 18 s^{2}+7.436 \mathrm{e} 18 s+1.985 \mathrm{e} 18,}{s^{16}+580.3 s^{15}+1.504 \mathrm{e} 05 s^{14}+2.304 \mathrm{e} 07 s^{13}+2.327 \mathrm{e} 09 s^{12}+1.635 \mathrm{e} 11 s^{11}+8.233 \mathrm{e} 12 s^{10}} \\
& +3.012 \mathrm{e} 14 s^{9}+8.036 \mathrm{e} 15 s^{8}+1.555 \mathrm{e} 17 s^{7}+2.151 \mathrm{e} 18 s^{6}+2.072 \mathrm{e} 19 s^{5}+1.333 \mathrm{e} 20 s^{4} \\
& +5.334 \mathrm{e} 20 s^{3}+1.171 \mathrm{e} 21 s^{2}+1.089 \mathrm{e} 21 s+2.784 \mathrm{e} 20 \text {. }
\end{aligned}
$$


Table 3. Steady-state values of $x_{n}, y_{n}, K_{n}$ on each tray using ode45 solver.

\begin{tabular}{lccccccrr}
\hline Trays & 16 & 15 & 14 & 13 & 12 & 11 & 10 \\
\hline$x_{n}$ & 0.9953 & 0.9739 & 0.9228 & 0.8168 & 0.6500 & 0.4746 & 0.3534 & 0.2920 \\
$y_{n}$ & 0.9992 & 0.9953 & 0.9855 & 0.9620 & 0.9134 & 0.8369 & 0.7564 & 0.7008 \\
$K_{n}$ & 0.1774 & 0.1839 & 0.2008 & 0.2442 & 0.3476 & 0.5475 & 0.8063 & 1.0143 \\
\hline Trays & 8 & 7 & 6 & 5 & 4 & 3 & 2 \\
\hline$x_{n}$ & 0.2727 & 0.2696 & 0.2622 & 0.2451 & 0.2104 & 0.1539 & 0.0883 \\
$y_{n}$ & 0.6805 & 0.6771 & 0.6687 & 0.6484 & 0.6022 & 0.5082 & 0.3549 & 0.1770 \\
$K_{n}$ & 1.0961 & 1.1102 & 1.1454 & 1.2320 & 1.4418 & 1.9192 & 2.8441 & 4.1441 \\
\hline
\end{tabular}

\section{Reduced order model formulation}

\section{$3.1 D P A$}

DPA computes dominant poles of the transfer function $G(s)$ based on the Newton method [17]. A pole $\lambda_{i}$ that corresponds to a residue $\left|R_{i}\right|$ with large magnitude $\left|R_{j}\right|$ is called a dominant pole. A dominant pole is well observable and controllable in the transfer function. This can also be observed from the corresponding Bode magnitude plot of $G(s)$, where peaks occur at frequencies close to the imaginary parts [18] of the dominant poles of $G(s)$.

$$
G(s)=\mathbf{C}(s \mathbf{I}-\mathbf{A})^{-1} \mathbf{B}=\sum_{i=1}^{n} \frac{R_{i}}{s-\lambda_{i}}
$$

The transfer function $G(s)$ can be expressed as a sum of residue matrices given by Eq. (15), where residue $R_{i}=\left(\mathbf{C} x_{i}\right)\left(y_{i} \mathbf{B}\right) \quad$ and $\quad x_{i}, \quad y_{i}, \quad \lambda_{i}$ are eigen-triplets $(i=1,2, \ldots, n)$

Consider a pole $\lambda=\alpha+j \beta$, with residue $R$; then it is shown that

$$
\begin{aligned}
\lim _{\omega \rightarrow \beta} G(j w)= & \lim _{\omega \rightarrow \beta} \frac{R}{[j w-(\alpha+j \beta)]} \\
& +\sum_{j=1}^{n-1} \frac{C}{\left[j w-\lambda_{j}\right]} \lim _{\omega \rightarrow \beta} G(j w) \\
= & \frac{R}{\alpha}+G_{n-1}(j \beta) .
\end{aligned}
$$

Hence pole $\lambda_{j}$ is dominant if $\left|\frac{R_{j}}{\operatorname{Re}\left(\lambda_{j}\right)}\right|$ is large and causes a peak in the Bode plot.

\subsection{Proposed hybrid algorithm}

The recently proposed hybrid algorithm [10], CDPA, combines the features of clustering method and DPA, and effectively matches the original system characteristics. The CDPA is described in table 4.
Table 4. CDPA algorithm.

Step 1: Given a transfer function $G(s)$

Step 2: Initialization

Step 3: Provide an initial eigenvalue estimate $s_{k}$

Step 4: Specify the values for the output at all iterations as unity, $y\left(s_{k}\right)=1$, where $k$ is the iteration count

Step 5: Set $k=0$

Step 6: Solve for $x_{k}$ from $\left(s_{k} \mathbf{I}-\mathbf{A}\right) x_{k}=\mathbf{B}$

Step 7: Solve for $y_{k}$ from $\left(s_{k} \mathbf{I}-\mathbf{A}\right) y_{k}=\mathbf{C}$

Step 8: Compute the new eigenvalue estimate $s_{k+1}$

Step 9: If the change in eigenvalue estimate is greater than convergence tolerance, then increase the iteration count $(k=k+1)$ and return to step 6

Step 10: Otherwise the algorithm has converged to the dominant pole

Step 11: These dominant poles are grouped into several clusters and then replaced by the corresponding cluster centres in the denominator polynomial

Step 12: Obtain the numerator polynomial using the factor division algorithm

In the CDPA method, the denominator polynomial of the reduced order model with respect to original model is determined by forming the clusters of the dominant poles and the coefficients of numerator polynomial with respect to original model are obtained using the factor division algorithm.

The poles of transfer function Eq. (15) are $\lambda \in \rightarrow C$ for which $\lim _{s \rightarrow \lambda}|G(s)|=\infty$.

Consider now the function $H(s)$ given by $H(s)=\frac{1}{G(s)}$ for $\lim _{s \rightarrow \lambda}|G(s)|=0$. In other words, the poles are the roots of $H(s)$ and these roots can be computed by Newton's method. This is the basic idea behind DPA [19].

$$
H^{\prime}(s)=\frac{-G^{\prime}(s)}{G^{2}(s)} .
$$


Solve $x_{k}$ from $\quad\left(s_{k} \mathbf{I}-\mathbf{A}\right) x_{k}=\mathbf{B} \quad$ and $y_{k}$ from $\left(s_{k} \mathbf{I}-\mathbf{A}\right) y_{k}=\mathbf{C}$. Then compute the new pole estimate as follows:

$$
s_{k+1}=s_{k}-\frac{\mathbf{C} x_{k}}{y_{k} \mathbf{I} x_{k}}=\frac{y_{k} \mathbf{A} x_{k}}{y_{k} \mathbf{I} x_{k}} .
$$

In CDPA, the dominant poles are grouped into several clusters and then replaced by the corresponding cluster centres. By the factor division algorithm, the coefficients of the numerator polynomial are determined [20, 21]. Now, consider the $n$ th-order linear dynamic system described by the transfer function as in Eq. 19:

$$
G(s)=\frac{N(s)}{D(s)}=\frac{e_{0}+e_{1} s+e_{2} s^{2}+\cdots+e_{n-1} s^{n-1}}{f_{0}+f_{1} s+f_{2} s^{2}+\cdots+f_{n} s^{n}}
$$

where $e_{i} ; 0 \leq i \leq n-1$ and $f_{i} ; 0 \leq i \leq n$ are scalar constants.

The corresponding $k$ th $(k<n)$-order reduced model is synthesized as follows:

$$
G_{k}(s)=\frac{N_{k}(s)}{D_{k}(s)}=\frac{a_{0}+a_{1} s+a_{2} s^{2}+\cdots+a_{k-1} s^{k-1}}{b_{0}+b_{1} s+b_{2} s^{2}+\cdots+b_{k} s^{k}}
$$

where $a_{i} ; 0 \leq i \leq k-1$ and $b_{i} ; 0 \leq i \leq k$ are scalar constants.

Let $r$ real poles in one cluster be $\left(p_{1}, p_{2}, p_{3}, \ldots, p_{r}\right)$; then the Inverse Distance Measure (IDM) criterion identifies the cluster centre, as in Eq. (21):

$$
p_{c}=\left\{\sum_{i=1}^{r} \frac{1}{p_{i}} / r\right\}^{-1}
$$

where $p_{\mathrm{c}}$ is cluster centre from $r$ real poles of the original system.

The power series of original $n$ th-order system can be expanded about $s=0$ as follows:

$$
G(s)=C_{0}+C_{1} s+C_{2} s^{2}+\cdots
$$

The power series expansion coefficients are determined as follows:

$$
\begin{gathered}
C_{0}=e_{0} / f_{0}, \\
C_{i}=\frac{1}{f_{0}}\left[e_{i}-\sum_{j=1}^{i} f_{j} C_{i-j}\right], i>0, \\
e_{i}=0, \quad i>n-1 .
\end{gathered}
$$

The reduced $k$ th-order model is written as

$$
G_{k}(s)=\frac{N_{k}(s)}{D_{k}(s)}=\frac{\sum_{i=0}^{k-1} a_{i} s^{i}}{\sum_{i=0}^{k} b_{i} s^{i}} .
$$

Reduced order transfer function matrix From input 1 to output...

$$
\begin{aligned}
& 1: \frac{0.002637 s+0.003613}{s^{2}+1.704 s+0.5211} \\
& 2: \frac{0.0007901 s+0.00103}{s^{2}+1.704 s+0.5211}
\end{aligned}
$$

From input 2 to output...

$$
\begin{aligned}
& 1: \frac{-0.007541 s-0.004013}{s^{2}+1.704 s+0.5211} \\
& 2: \frac{-0.0003125 s-0.000404}{s^{2}+1.704 s+0.5211}
\end{aligned}
$$

\section{MPC strategy}

The model is governed by the first-principle differential equation of a multivariable nonlinear binary distillation column process. MPC can be directly used to control a great variety of simple or complex processes, with long delay times, non-minimum phase or unstable process. It can also be applied for multivariable processes with dead times [22, 23]. Knowing the future reference signals, constraints on input, state and output variable are part of the controller, and optimal control actions are calculated, for example quadratic programming (QP) [24].

The finite horizon quadratic criterion is considered and the task is to minimize a quadratic cost function of the control error and the manipulated variable increments during the corresponding prediction horizons as described by

$$
\begin{aligned}
J= & \sum_{i=1}^{n_{y}} \sum_{j=N_{1}}^{N_{1}+N_{2}} p_{i}\left[\hat{y}_{i}(k+j)-r_{i}(k+j)\right]^{2} \\
& +\sum_{i=1}^{n_{u}} \sum_{j=1}^{N 3} q_{i}\left[\Delta u_{i}(k+j-1)\right]^{2}
\end{aligned}
$$

where $\hat{y}_{i}(k+j)$ is an optimum $j$-step ahead prediction of $i$ th output of the system, $N_{2}$ is the control error horizon, $N_{3}$ is the control horizon and $r_{i}(k+j)$ is the future set-point or reference for the $i$ th controlled variable. The parameters $p_{i}$ and $q_{i}$ are the weighting coefficient for control errors and control increments, respectively; $\Delta u_{i}(k+j-1)$ is the control increment of the $i$ th input; $n_{u}$ and $n_{y}$ are the number of inputs and number of outputs (manipulated and controlled variables).

The cost function consists of two parts, mainly costs due to control error in the control error horizon $N_{2}$, which is also called the optimization or prediction horizon, and another is costs to penalize the control signal increments or decrement (control rate) in the manipulated variable horizon $N_{3}$, which is also called the control horizon. For simplicity, in the following text, let $N_{1}=0, N_{2}=N_{3}=N$.

The basic structure of MPC algorithm [25] is shown in figure 2. At each time instant $k$ : 


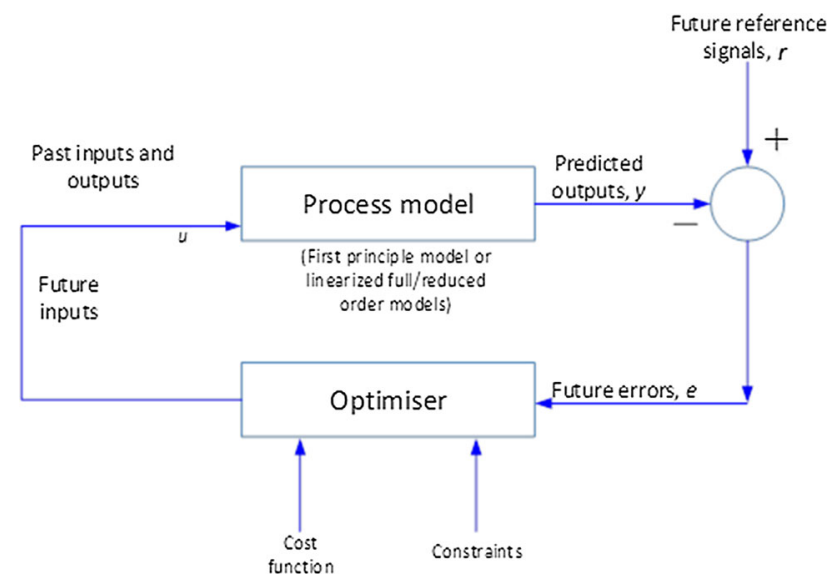

Figure 2. Structure of MPC.

1) The future outputs on the prediction horizon $N$ are predicted using the process model. Predicted outputs $y(k+i)$ for $i=1, \ldots, N$ depend on the past inputs and outputs and on the future control signals $u(k+i)$ for $i=0, \ldots, N-1$, which are to be calculated.

2) The set of future control signals is calculated by an optimizing criterion in order to keep the process as close as possible to the reference trajectory. If the model is linear and there are no constraints, an explicit solution can be obtained; otherwise, an iterative optimization method has to be used.

3) The control signal $u(k)$ is given to the process while the next calculated control signals are rejected. At the next sampling instant, $y(k+1)$ is known and step 1 is repeated with this new value using the receding horizon concept.

\subsection{GPC design for MIMO process}

The most common transfer function model with MPC is CARIMA model. When a plant operates around a particular working point, after linearization, it can be described by a CARIMA model $[26,27]$. The chosen model has importance when the uncertainty is included in a way that is a good representation of slow varying disturbances under non-zero steady-state condition.

This model is appropriate for applications in which disturbances are non-stationary and the resulting controller has an integrating behaviour. The reason a CARIMA model is used is that it incorporates a disturbance estimate and gives

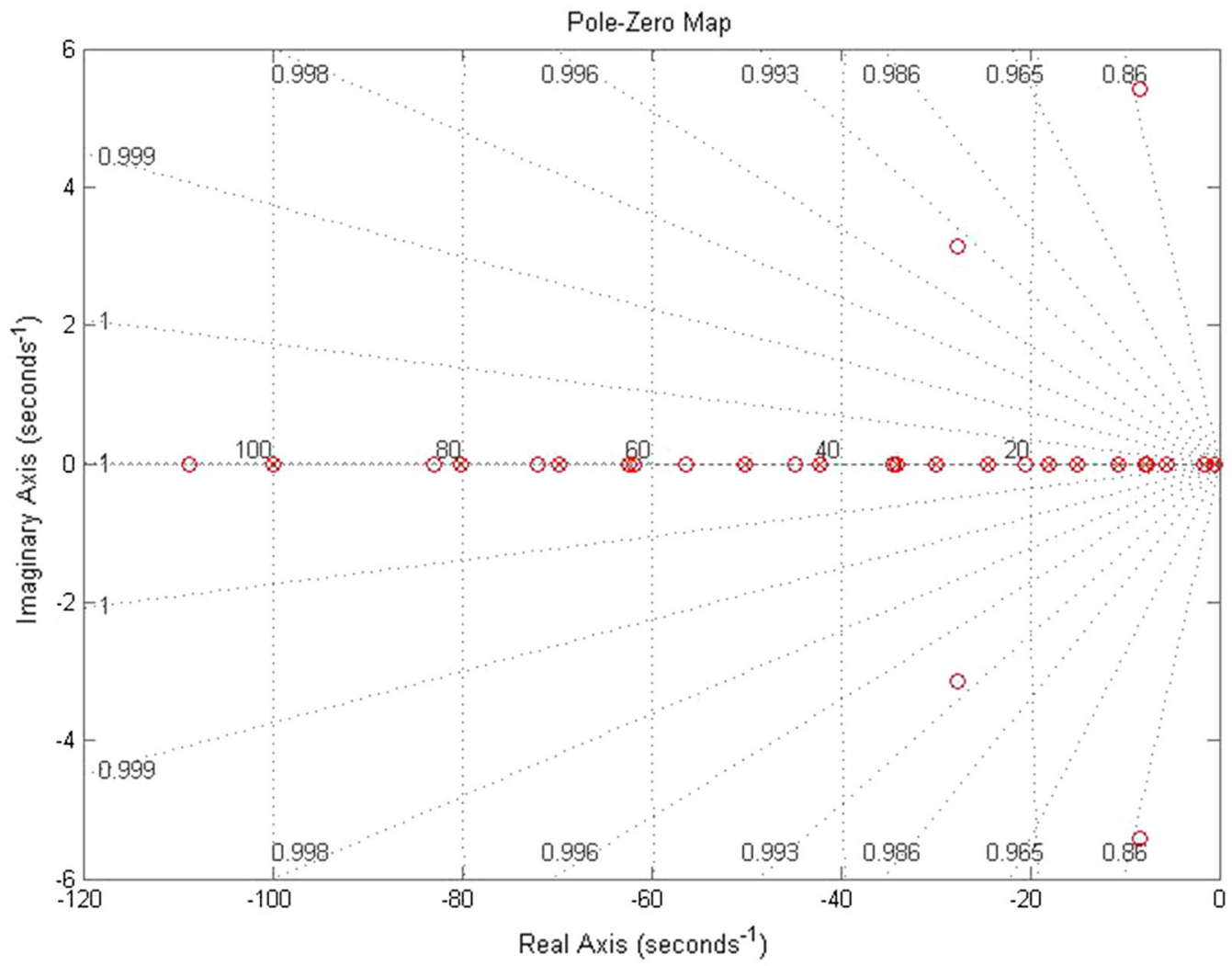

Figure 3. Pole-zero mapping for full order binary distillation column; ' $x$ ' refers to poles and 'o' refers to zeros. 


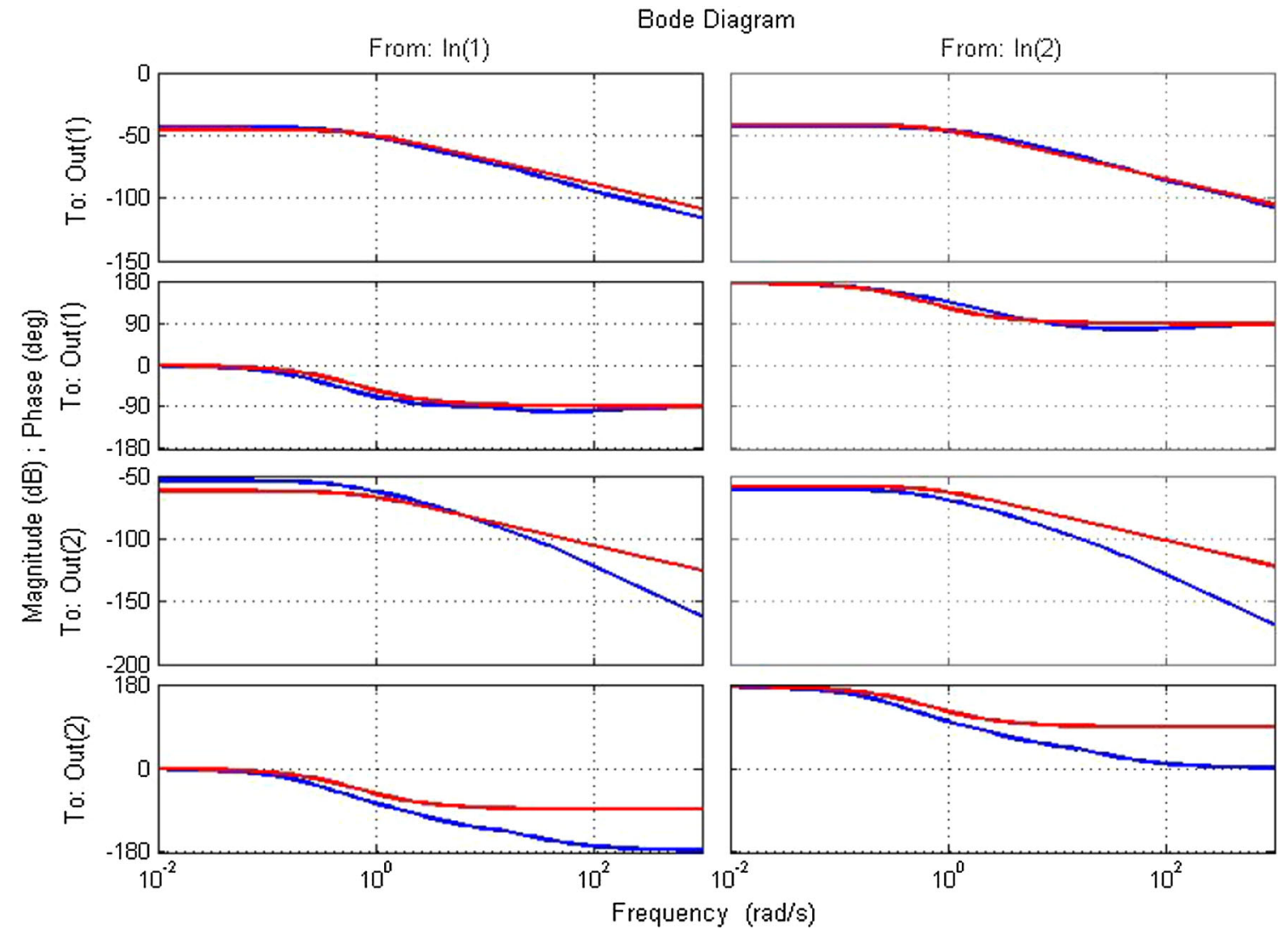

Figure 4. Bode plot for full order and reduced order model of a binary distillation column. $\operatorname{In}(1)$ refers to $L, \operatorname{In}(2) \operatorname{refers}$ to $V$, Out(1) refers to $X_{B}$ and $\operatorname{Out}(2)$ refers to $X_{D}$.

unbiased prediction in steady state, irrespective of some parameter uncertainty [28].

The control objective is to compute a future control sequence that the future plant output is driven similar to the reference trajectory. This is accomplished by minimizing quadratic cost function defined over the prediction horizon [29].

4.1a GPC with transfer function model: CARIMA model for a Two Input Two Output (TITO) [3, 25] multivariable process can be expressed as

$$
\begin{aligned}
\mathrm{A}_{1}\left(z^{-1}\right) \mathrm{y}_{1}(k)= & \mathrm{B}_{11}\left(z^{-1}\right) \mathrm{u}_{1}(k-1)+\mathrm{B}_{12}\left(z^{-1}\right) \mathrm{u}_{2}(k-1) \\
& +\frac{\mathrm{C}_{1}\left(z^{-1}\right)}{\Delta} \mathrm{e}_{1}(k)
\end{aligned}
$$

$$
\begin{aligned}
\mathrm{A}_{2}\left(z^{-1}\right) \mathrm{y}_{2}(k)= & \mathrm{B}_{21}\left(z^{-1}\right) \mathrm{u}_{1}(k-1)+\mathrm{B}_{22}\left(z^{-1}\right) \mathrm{u}_{2}(k-1) \\
& +\frac{\mathrm{C}_{2}\left(z^{-1}\right)}{\Delta} \mathrm{e}_{2}(k)
\end{aligned}
$$

where $A_{1}\left(z^{-1}\right), A_{2}\left(z^{-1}\right), B_{11}\left(z^{-1}\right), B_{12}\left(z^{-1}\right), B_{21}\left(z^{-1}\right), B_{22}\left(z^{-1}\right)$, $C_{1}\left(z^{-1}\right)$ and $C_{2}\left(z^{-1}\right)$ are polynomials defined as follows:

$$
\begin{aligned}
\mathrm{A}_{1}\left(z^{-1}\right) & =1+a_{11} z^{-1}+a_{12} z^{-2}+\cdots+a_{1 n} z^{-n} \\
\mathrm{~A}_{2}\left(z^{-1}\right) & =1+a_{21} z^{-1}+a_{22} z^{-2}+\cdots+a_{2 n} z^{-n} \\
\mathrm{~B}_{11}\left(z^{-1}\right) & =b_{111}+b_{112} z^{-1}+b_{113} z^{-2}+\cdots+b_{11 n} z^{-n+1} \\
\mathrm{~B}_{12}\left(z^{-1}\right) & =b_{121}+b_{122} z^{-1}+b_{123} z^{-2}+\cdots+b_{12 n} z^{-n+1} \\
\mathrm{~B}_{21}\left(z^{-1}\right) & =b_{211}+b_{212} z^{-1}+b_{213} z^{-2}+\cdots+b_{21 n} z^{-n+1} \\
\mathrm{~B}_{22}\left(z^{-1}\right) & =b_{221}+b_{222} z^{-1}+b_{223} z^{-2}+\cdots+b_{22 n} z^{-n+1} \\
\mathrm{C}_{1}\left(z^{-1}\right) & =1+c_{11} z^{-1}+c_{12} z^{-2}+\cdots+c_{1 n_{c}} z^{-n_{c}} \\
\mathrm{C}_{2}\left(z^{-1}\right) & =1+c_{21} z^{-1}+c_{22} z^{-2}+\cdots+c_{2 n_{c}} z^{-n_{c}}
\end{aligned}
$$

The operator $\Delta$ is defined as $\Delta=1-z^{-1}$. The variables $y_{1}(k), y_{2}(k), u_{1}(k), u_{2}(k), e_{1}(k)$ and $e_{2}(k)$ are output, input and noise, respectively. The noise is supposed to be white noise random signal with zero mean.

Polynomials $A_{1}\left(z^{-1}\right), A_{2}\left(z^{-1}\right)$ and $B_{11}\left(z^{-1}\right), B_{12}\left(z^{-1}\right)$, $B_{21}\left(z^{-1}\right), B_{22}\left(z^{-1}\right)$ are denominator and numerator of transfer function, respectively. Polynomials $C_{1}\left(z^{-1}\right)$ and $C_{2}\left(z^{-1}\right)$ are disturbance model polynomials or can be seen as a filtering polynomial. Rearranging the terms from the relations 


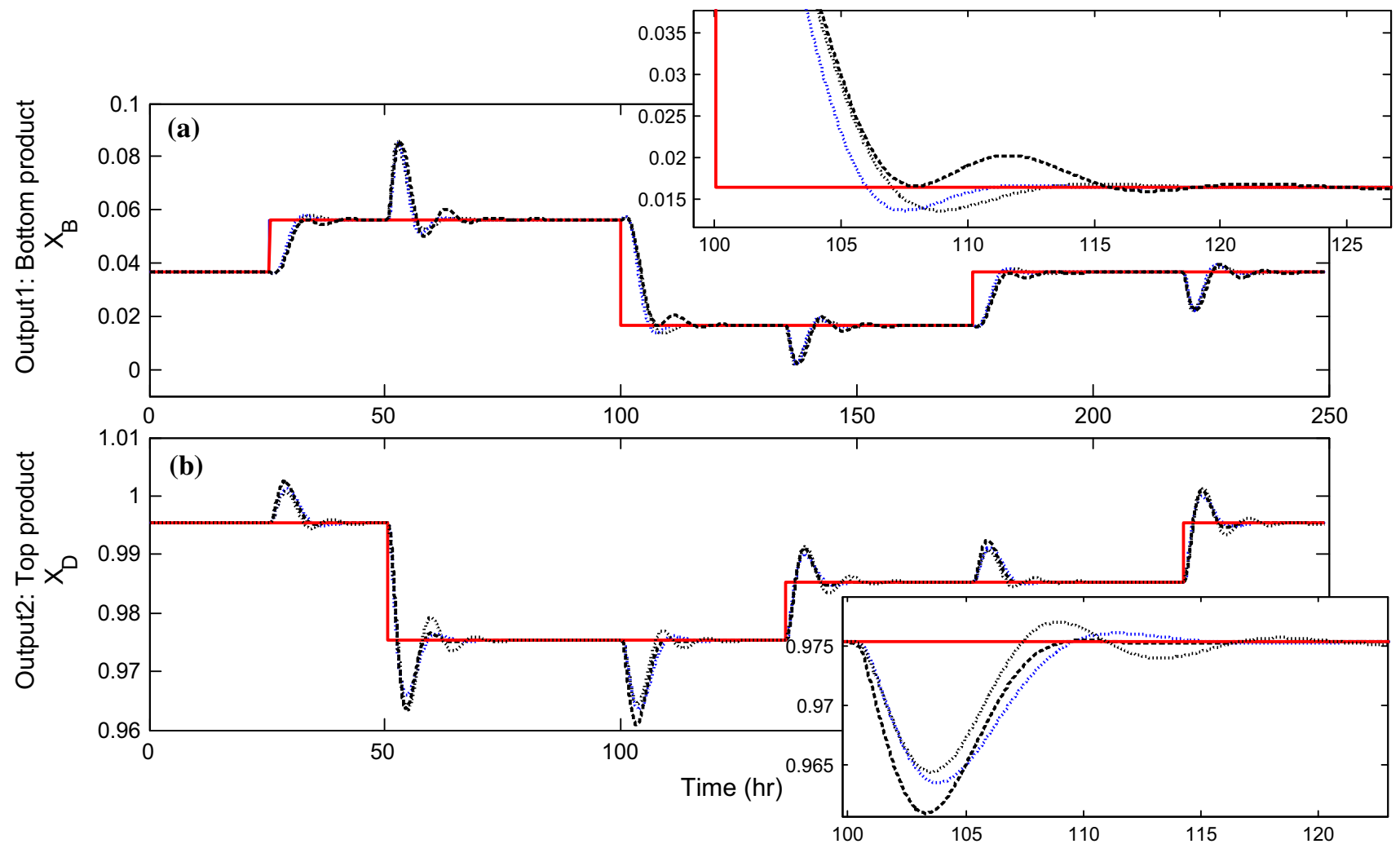

Figure 5. Comparative output responses of a binary distillation column with PID controller tuned using various models for (a) bottom product and (b) top product.

$$
\begin{aligned}
& \Delta \mathrm{A}_{1}\left(z^{-1}\right) \mathrm{y}_{1}(k)=\mathrm{B}_{11}\left(z^{-1}\right) \Delta \mathrm{u}_{1}(k-1) \\
& \quad+\mathrm{B}_{12}\left(z^{-1}\right) \Delta \mathrm{u}_{2}(k-1)+\mathrm{C}_{1}\left(z^{-1}\right) \mathrm{e}_{1}(k) \\
& \left(1-z^{-1}\right) \mathrm{A}_{1}\left(z^{-1}\right) \mathrm{y}_{1}(k)=\mathrm{B}_{11}\left(z^{-1}\right) \Delta \mathrm{u}_{1}(k-1) \\
& \quad+\mathrm{B}_{12}\left(z^{-1}\right) \Delta \mathrm{u}_{2}(k-1)+\mathrm{C}_{1}\left(z^{-1}\right) \mathrm{e}_{1}(k) \\
& \left(1-z^{-1}\right)\left(1+a_{11} z^{-1}+a_{12} z^{-2}+\cdots+a_{1 n} z^{-n}\right) \mathrm{y}_{1}(k) \\
& \quad=\left(b_{111}+b_{112} z^{-1}+b_{113} z^{-2}\right. \\
& \left.\quad+\cdots+b_{11 n} z^{-n+1}\right) \Delta \mathrm{u}_{1}(k-1) \\
& \quad+\left(b_{121}+b_{122} z^{-1}+b_{123} z^{-2}+\cdots+b_{12 n} z^{-n+1}\right) \\
& \Delta \mathrm{u}_{2}(k-1)+\left(1+c_{11} z^{-1}+c_{12} z^{-2}\right. \\
& \left.\quad+\cdots+c_{1 n_{c}} z^{-n_{c}}\right) \mathrm{e}_{1}(k)
\end{aligned}
$$

the difference equation for step $k+1$ for the first output is obtained as

$$
\begin{aligned}
\hat{\mathrm{y}}_{1}(k & +1)+\left(a_{11}-1\right) \mathrm{y}_{1}(k)+\left(a_{12}-a_{11}\right) \mathrm{y}_{1}(k-1) \\
& +\cdots+\left(-a_{1 n}\right) \mathrm{y}_{1}(k-n) \\
= & b_{111} \Delta \mathrm{u}_{1}(k)+b_{112} \Delta \mathrm{u}_{1}(k-1) \\
+ & \cdots+b_{11 n} \Delta \mathrm{u}_{1}(k-n+1) \\
& +b_{121} \Delta \mathrm{u}_{2}(k)+b_{122} \Delta \mathrm{u}_{2}(k-1) \\
& +\cdots+b_{12 n} \Delta \mathrm{u}_{2}(k-n+1) \\
& +\mathrm{e}_{1}(k+1)+c_{11} \mathrm{e}_{1}(k)+\cdots+c_{1 n_{c}} \mathrm{e}_{1}\left(k-n_{c}+1\right)
\end{aligned}
$$

The difference equation for step $k+2$ is obtained as

$$
\begin{aligned}
\hat{\mathrm{y}}_{1}(k+2)+\left(a_{11}-1\right) \hat{\mathrm{y}}_{1}(k+1)+\left(a_{12}-a_{11}\right) \mathrm{y}_{1}(k) \\
+\cdots+\left(-a_{1 n}\right) \mathrm{y}_{1}(k-n+1) \\
=b_{111} \Delta \mathrm{u}_{1}(k+1)+b_{112} \Delta \mathrm{u}_{1}(k) \\
+\cdots+b_{11 n} \Delta \mathrm{u}_{1}(k-n+2) \\
\quad+b_{121} \Delta \mathrm{u}_{2}(k+1)+b_{122} \Delta \mathrm{u}_{2}(k) \\
+\cdots+b_{12 n} \Delta \mathrm{u}_{2}(k-n+2) \\
\quad+\mathrm{e}_{1}(k+2)+c_{11} \mathrm{e}_{1}(k+1) \\
+\cdots+c_{1 n_{c}} \mathrm{e}_{1}\left(k-n_{c}+2\right)
\end{aligned}
$$

Similarly, the difference equation for step $k+N$ for the first output $y_{1}$ is obtained as

$$
\begin{aligned}
\hat{\mathrm{y}}_{1}(k+N)+\left(a_{11}-1\right) \hat{\mathrm{y}}_{1}(k+N-1) \\
+\left(a_{12}-a_{11}\right) \hat{\mathrm{y}}_{1}(k+N-2)+\cdots \\
\quad+\left(-a_{1 n}\right) \hat{\mathrm{y}}_{1}(k+N-n-1)=b_{111} \Delta \mathrm{u}_{1}(k+N-1) \\
+b_{112} \Delta \mathrm{u}_{1}(k+N-2)+\cdots+b_{11 n} \Delta \mathrm{u}_{1}(k+N-n) \\
\quad+b_{121} \Delta \mathrm{u}_{2}(k+N-1)+b_{122} \Delta \mathrm{u}_{2}(k+N-2) \\
+\cdots+b_{12 n} \Delta \mathrm{u}_{2}(k+N-n) \\
\quad+\mathrm{e}_{1}(k+N)+c_{11} \mathrm{e}(k+N-1)+c_{12} \mathrm{e}_{1}(k+N-2) \\
+\cdots+c_{1 n_{c}} \mathrm{e}_{1}\left(k+N-n_{c}\right)
\end{aligned}
$$


Assume $\quad \mathrm{e}_{1}(k+1)=\mathrm{e}_{1}(k+2)=\cdots=\mathrm{e}_{1}(k+N)=0$. Separating variables in vectors that create forced and free response of the system and rewriting Eqs. (30)-(32) in matrix form, Eq. (33) is obtained:

$$
\begin{aligned}
& \Delta \mathbf{A}_{1} \underbrace{\left[\begin{array}{c}
\hat{\mathbf{y}}_{1}(k+1) \\
\hat{\mathbf{y}}_{1}(k+2) \\
\vdots \\
\hat{\mathbf{y}}_{1}(k+N)
\end{array}\right]}_{\hat{\mathbf{y}}_{1}}=\mathbf{B}_{11}^{\left[\begin{array}{c}
\Delta \mathrm{u}_{1}(k) \\
\Delta \mathrm{u}_{1}(k+1) \\
\vdots \\
\\
\Delta \mathrm{u}_{1}(k+N-1)
\end{array}\right]} \\
& +\mathbf{B}_{12} \underbrace{\left[\begin{array}{c}
\Delta \mathrm{u}_{2}(k) \\
\Delta \mathrm{u}_{2}(k+1) \\
\vdots \\
\Delta \mathrm{u}_{2}(k+N-1)
\end{array}\right]}_{\Delta \mathbf{U}_{2}}+\mathbf{A}_{\mathrm{p} 1}^{\left[\begin{array}{c}
\mathrm{y}_{1}(k) \\
\mathrm{y}_{1}(k-1) \\
\vdots \\
\mathrm{y}_{1}(k-n)
\end{array}\right]} \\
& +\mathbf{B}_{p 11} \underbrace{\left[\begin{array}{c}
\Delta \mathrm{u}_{1}(k-1) \\
\Delta \mathrm{u}_{1}(k-2) \\
\vdots \\
\Delta \mathrm{u}_{1}(k-n+1)
\end{array}\right]}_{\Delta \mathbf{U}_{\mathrm{p} 1}}+B_{p 12} \underbrace{\left[\begin{array}{c}
\Delta \mathrm{u} 2(k-1) \\
\Delta \mathrm{u}_{2}(k-2) \\
\vdots \\
\Delta \mathrm{u}_{2}(k-n+1)
\end{array}\right]}_{\Delta \mathbf{U}_{\mathrm{p} 2}} \\
& C_{p 1} \underbrace{\left[\begin{array}{c}
\mathrm{e}_{1}(k) \\
\mathrm{e}_{1}(k-1) \\
\vdots \\
\mathrm{e}_{1}\left(k-n_{c}+1\right)
\end{array}\right]}_{\mathbf{E}_{1}}
\end{aligned}
$$

Similarly, difference equation for step $k+N$ for the second output $y_{2}$ is obtained as

$$
\begin{aligned}
& \hat{\mathrm{y}}_{2}(+N)+\left(a_{21}-1\right) \hat{\mathrm{y}}_{2}(k+N-1) \\
&+\left(a_{22}-a_{21}\right) \hat{\mathrm{y}}_{2}(k+N-2)+\cdots \\
&+\left(-a_{2 n}\right) \hat{\mathrm{y}}_{2}(k+N-n-1)=b_{211} \Delta \mathrm{u}_{1}(k+N-1) \\
&+ b_{212} \Delta \mathrm{u}_{1}(k+N-2)+\cdots+b_{21 n} \Delta \mathrm{u}_{1}(k+N-n) \\
&+b_{221} \Delta \mathrm{u}_{2}(k+N-1)+b_{222} \Delta \mathrm{u}_{2}(k+N-2) \\
&+ \cdots+b_{22 n} \Delta \mathrm{u}_{2}(k+N-n) \\
&+\mathrm{e}_{2}(k+N)+c_{21} \mathrm{e}(k+N-1)+c_{22} \mathrm{e}_{2} \\
&(k+N-2)+\cdots+c_{2 n_{c}} \mathrm{e}_{2}\left(k+N-n_{c}\right)
\end{aligned}
$$

Assume $\quad \mathrm{e}_{2}(k+1)=\mathrm{e}_{2}(k+2)=\cdots=\mathrm{e}_{2}(k+N)=0$. Separating variables in vectors that create forced and free response of the system and rewriting in matrix form gives the following relation:
$\Delta \mathbf{A}_{2} \underbrace{\left[\begin{array}{c}\hat{\mathbf{y}}_{2}(k+1) \\ \hat{\mathbf{y}}_{2}(k+2) \\ \vdots \\ \hat{\mathbf{y}}_{2}(k+N)\end{array}\right]}_{\hat{\mathbf{Y}} 2}=\mathbf{B}_{21}^{\left[\begin{array}{c}\Delta \mathrm{u}_{1}(k) \\ \Delta \mathrm{u}_{1}(k+1) \\ \vdots \\ \Delta \mathrm{u}_{1}(k+N-1)\end{array}\right]}$

$$
+\mathbf{B}_{22} \underbrace{\left[\begin{array}{c}
\Delta \mathrm{u}_{2}(k) \\
\Delta \mathrm{u}_{2}(k+1) \\
\vdots \\
\Delta \mathrm{u}_{2}(k+N-1)
\end{array}\right]}_{\Delta \mathbf{U}_{2}}+\mathbf{A}_{\mathrm{p} 22}^{\left[\begin{array}{c}
\mathrm{y}_{2}(k) \\
\mathrm{y}_{2}(k-1) \\
\vdots \\
\mathrm{y}_{2}(k-n)
\end{array}\right]}
$$$$
+\mathbf{B}_{\mathrm{p} 21} \underbrace{\left[\begin{array}{c}
\Delta \mathrm{u}_{1}(k-1) \\
\Delta \mathrm{u}_{1}(k-2) \\
\vdots \\
\Delta \mathrm{u}_{1}(k-n+1)
\end{array}\right]}_{\Delta \mathbf{U p}_{1}}+\mathbf{B}_{\mathrm{p} 22} \underbrace{\left[\begin{array}{c}
\Delta \mathrm{u}_{2}(k-1) \\
\Delta \mathrm{u}_{2}(k-2) \\
\vdots \\
\Delta \mathrm{u}_{2}(k-n+1)
\end{array}\right]}_{\Delta \mathbf{U}_{\mathrm{p} 2}}
$$$$
\mathbf{C}_{\mathrm{p} 2} \underbrace{\left[\begin{array}{c}
\mathrm{e}_{1}(k) \\
\mathrm{e}_{1}(k-1) \\
\vdots \\
\mathrm{e}_{1}\left(k-n_{c}+1\right)
\end{array}\right]}_{\mathbf{E}_{2}}
$$

Rearranging first and second output variables into a single matrix, the resultant matrix is as described in Eq. (36):

$$
\mathbf{A} \hat{\mathbf{Y}}=\mathbf{B U}+\mathbf{A}_{\mathbf{p}} \mathbf{Y}_{\mathbf{p}}+\mathbf{C}_{\mathbf{p}} \mathbf{E}_{\mathbf{p}}+\mathbf{B}_{\mathbf{p}} \mathbf{U}_{\mathbf{p}}
$$

where $\mathbf{A}, \mathbf{B}, \mathbf{A}_{\mathrm{p}}, \mathbf{C}_{\mathrm{p}}$ and $\mathbf{B}_{\mathrm{p}}$ matrices are filled with corresponding coefficients from Eq. (35):

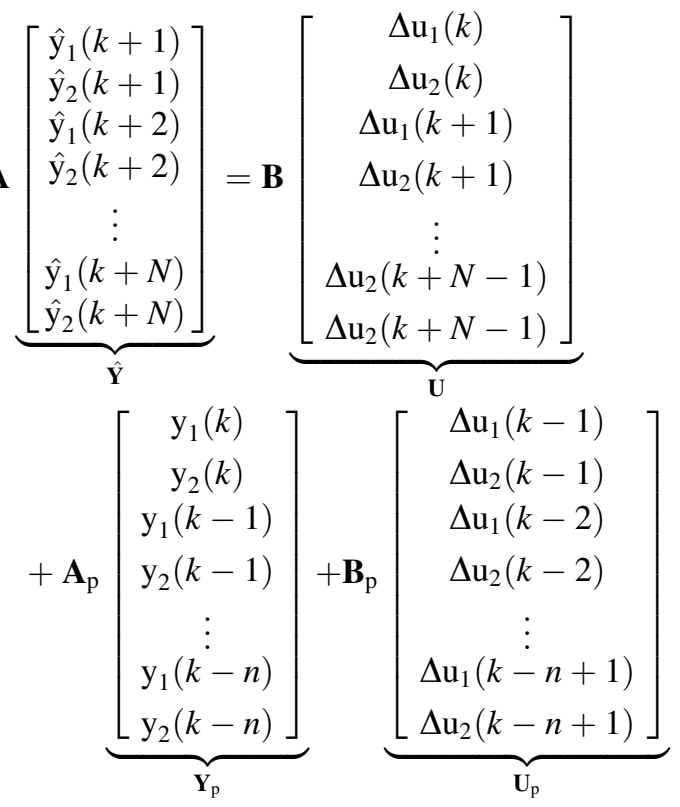




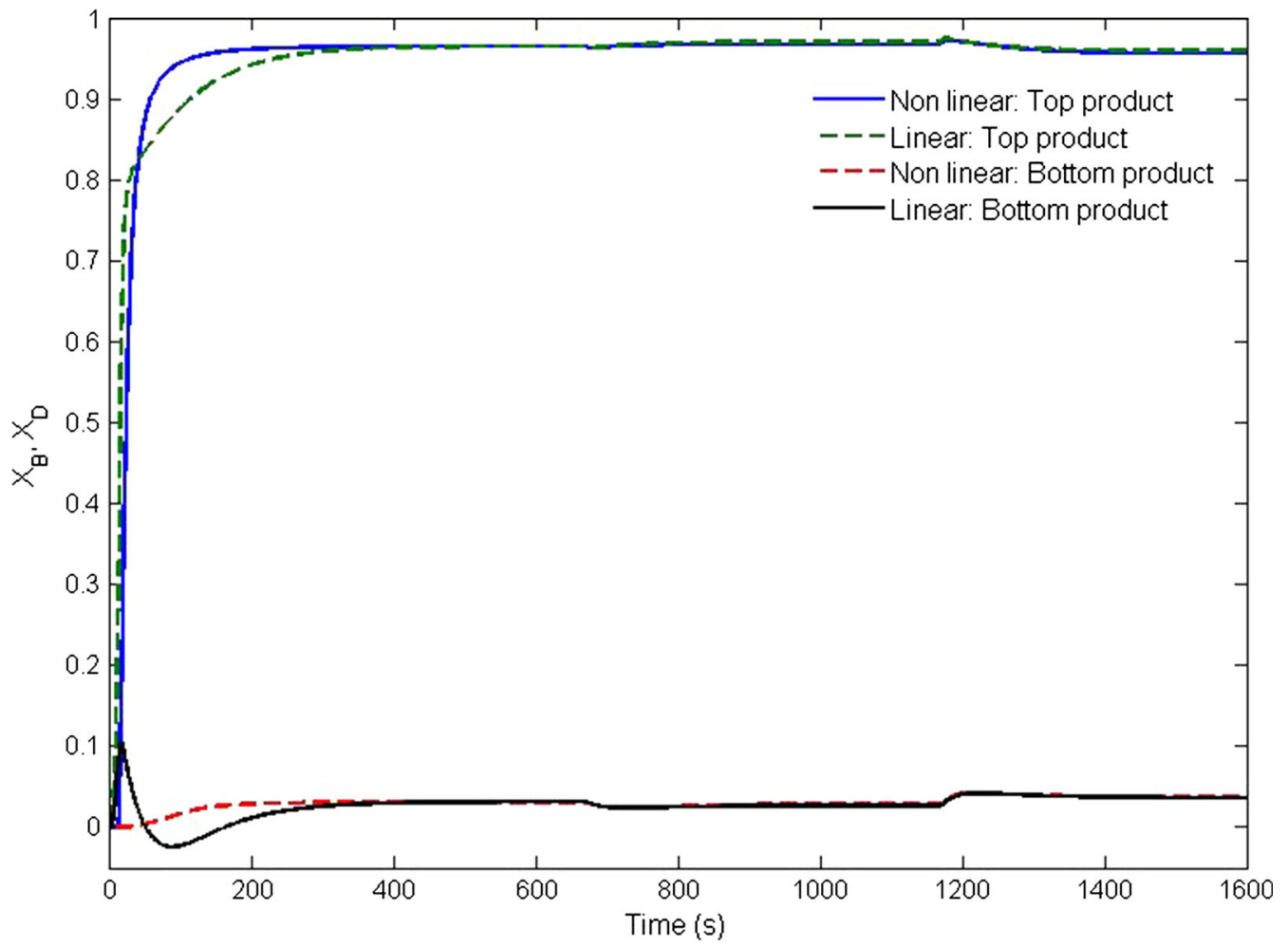

Figure 6. 5\% change in feed composition variation as a disturbance in a distillation column.

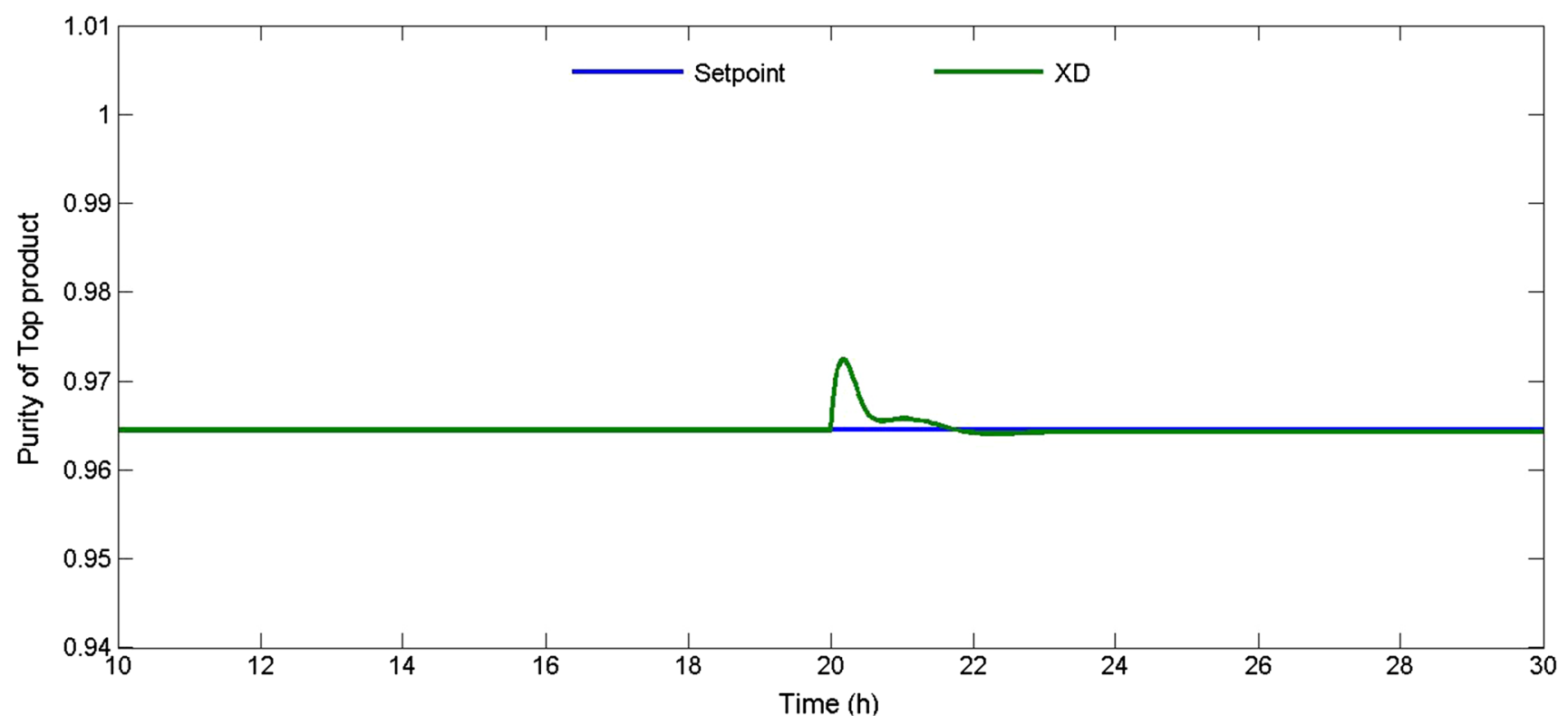

Figure 7. Regulatory response of the simulated model based controller for top product quality. 
Table 5. PID controller design.

\begin{tabular}{|c|c|c|c|c|c|c|c|c|c|}
\hline \multirow[b]{2}{*}{ Compositions } & \multicolumn{3}{|c|}{ Linearized full order model } & \multicolumn{3}{|c|}{ Linearized reduced order model } & \multicolumn{3}{|c|}{ First-principle model } \\
\hline & $K_{\mathrm{P}}$ & $K_{\mathrm{I}}$ & $K_{\mathrm{D}}$ & $K_{\mathrm{P}}$ & $K_{\mathrm{I}}$ & $K_{\mathrm{D}}$ & $K_{\mathrm{P}}$ & $K_{\mathrm{I}}$ & $K_{\mathrm{D}}$ \\
\hline Bottom product & 108.5052 & 207.1671 & - & 182.3268 & 220.3698 & - & 139.5425 & 170.1675 & - \\
\hline Top product & 223.0076 & 159.0710 & -74.6747 & 212.9030 & 126.1064 & -135.5175 & 110.1067 & 200.1211 & 5.6700 \\
\hline
\end{tabular}

$$
+\mathbf{C}_{\mathrm{p}} \underbrace{\left[\begin{array}{c}
\mathrm{e}_{1}(k) \\
\mathrm{e}_{2}(k) \\
\mathrm{e}(k-1) \\
\mathrm{e}(k-1) \\
\vdots \\
\mathrm{e}_{1}\left(k-n_{c}+1\right) \\
\mathrm{e}_{2}\left(k-n_{c}+1\right)
\end{array}\right]}_{\mathbf{E}_{\mathrm{p}}} .
$$

Multiplying $\mathbf{A}^{-1}$ on both sides in Eq. (36), $\hat{\mathbf{Y}}$ is given by Eq. (38):

$$
\hat{\mathbf{Y}}=\underbrace{\underbrace{\mathbf{A}^{-1} \mathbf{B}}_{\mathrm{G}} \mathbf{U}}_{\text {Fored response }}+\underbrace{\underbrace{\mathbf{A}^{-1} \mathbf{A}_{\mathrm{p}}}_{\mathbf{F}_{\mathrm{y}}} \mathbf{Y}_{\mathrm{p}}+\underbrace{\mathbf{A}^{-1} \mathbf{B}_{\mathrm{p}}}_{\mathbf{F}_{\mathrm{u}}} \mathbf{U}_{\mathrm{p}}+\underbrace{\mathbf{A}^{-1} \mathbf{C}_{\mathrm{p}}}_{\mathbf{F}_{\mathrm{e}}} \mathbf{E}_{\mathrm{p}}}_{\text {Free response }} .
$$

The prediction of the output is separated into two parts free response and forced response. The simplified representation of the combined predicted output is as given in Eq. (39):

$$
\hat{\mathbf{Y}}=\mathbf{G U}+\underbrace{\left[\begin{array}{ccc}
\mathbf{F}_{\mathrm{y}} & \mathbf{F}_{\mathrm{u}} & \mathbf{F}_{\mathrm{e}}
\end{array}\right]}_{\mathbf{F}} \underbrace{\left[\begin{array}{c}
\mathbf{Y}_{\mathrm{p}} \\
\mathbf{U}_{\mathrm{p}} \\
\mathbf{E}_{\mathrm{p}}
\end{array}\right]}_{\mathbf{X}}=\mathbf{G U}+\underbrace{\mathbf{F X}}_{\mathrm{f}}
$$

4.1b Cost function: The cost function in Eq. (27) can be represented in matrix format as

$$
\mathbf{J}=(\hat{\mathbf{Y}}-\mathbf{r})^{\mathrm{T}} \mathbf{P}(\hat{\mathbf{Y}}-\mathbf{r})+\mathbf{U}^{\mathrm{T}} \mathbf{Q} \mathbf{U}
$$

where $\mathbf{P}$ and $\mathbf{Q}$ are diagonal matrix with diagonal elements $p$ and $q$, respectively.

$$
\mathbf{r}=\left[\begin{array}{c}
r_{1}(k+1) \\
r_{2}(k+1) \\
r_{1}(k+2) \\
r_{2}(k+2) \\
\vdots \\
r_{1}(k+N) \\
r_{2}(k+N)
\end{array}\right] .
$$

Substituting $\hat{\mathbf{Y}}$ from Eq. (39) gives

$$
\mathbf{J}=(\mathbf{G U}+\mathbf{f}-\mathbf{r})^{\mathrm{T}} \mathbf{P}(\mathbf{G U}+\mathbf{f}-\mathbf{r})+\mathbf{U}^{\mathrm{T}} \mathbf{Q} \mathbf{U}
$$

$$
\mathbf{J}=\mathbf{U}^{\mathrm{T}} \mathbf{M} \mathbf{U}+\mathbf{2} \mathbf{m}^{\mathrm{T}} \mathbf{U}+\mathbf{k}
$$

where

$$
\begin{aligned}
& \mathbf{M}=\mathbf{G}^{\mathrm{T}} \mathbf{P G}+\mathbf{Q}, \quad \mathbf{m}^{\mathrm{T}}=(\mathbf{f}-\mathbf{r})^{\mathrm{T}} \mathbf{P}^{T} \mathbf{G} \\
& \mathbf{k}=\mathbf{f}^{\mathrm{T}} \mathbf{P} \mathbf{f}-\mathbf{2} \mathbf{f}^{\mathrm{T}} \mathbf{P r}+\mathbf{r}^{\mathrm{T}} \mathbf{P r} .
\end{aligned}
$$

The control law for unconstrained MPC cost function minimization is

$$
\mathbf{U}=-\mathbf{M}^{-1} \mathbf{m}=\underbrace{\left(\mathbf{G}^{\mathrm{T}} \mathbf{P G}+\mathbf{Q}\right)^{-1} \mathbf{G}^{\mathrm{T}} \mathbf{P}}_{\mathbf{L}}(\mathbf{r}-\mathbf{f}) .
$$

First two rows $\mathbf{K}_{1}$ and $\mathbf{K}_{2}$ in $\mathbf{L}$ correspond to control action at time $k$ :

$$
\left[\begin{array}{l}
\Delta \mathrm{u}_{1}(k) \\
\Delta \mathrm{u}_{2}(k)
\end{array}\right]=\mathbf{K}(\mathbf{r}-\mathbf{f})
$$

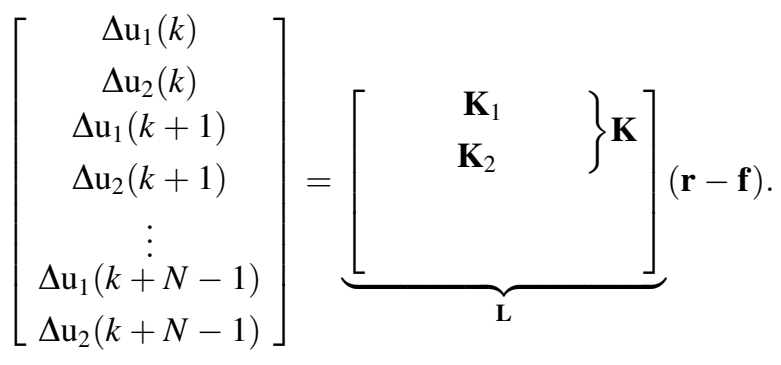

4.1c Constraints: In a long-range predictive control, the controller has to anticipate constraint violation and correct them in an appropriate way. The output constraints are mainly due to safety reasons and must be controlled in advance, because output variables are affected by process dynamics [30]. Input/manipulated variables can always be kept bounded, by limiting the control action to an appropriate value satisfying the constraints [31]. The TITO constraints are described in Eqs. (46) and (47):

$$
\begin{gathered}
\mathrm{u}_{1 \min } \leq \mathrm{u}_{1}(k+i-1) \leq \mathrm{u}_{1 \max } ; \mathrm{y}_{1 \min } \leq \mathrm{y}_{1}(k+i) \leq \mathrm{y}_{1 \max } ; \\
i=\{1, N\}, \\
\quad \mathrm{u}_{2 \min } \leq \mathrm{u}_{2}(k+i-1) \leq \mathrm{u}_{2 \max } ; \\
\quad \mathrm{y}_{2 \min } \leq \mathrm{y}_{2}(k+i) \leq \mathrm{y}_{2 \max } ; i=\{1, N\} .
\end{gathered}
$$

The implementation of MPC with constraints involves the minimization of a quadratic cost function subject to linear 


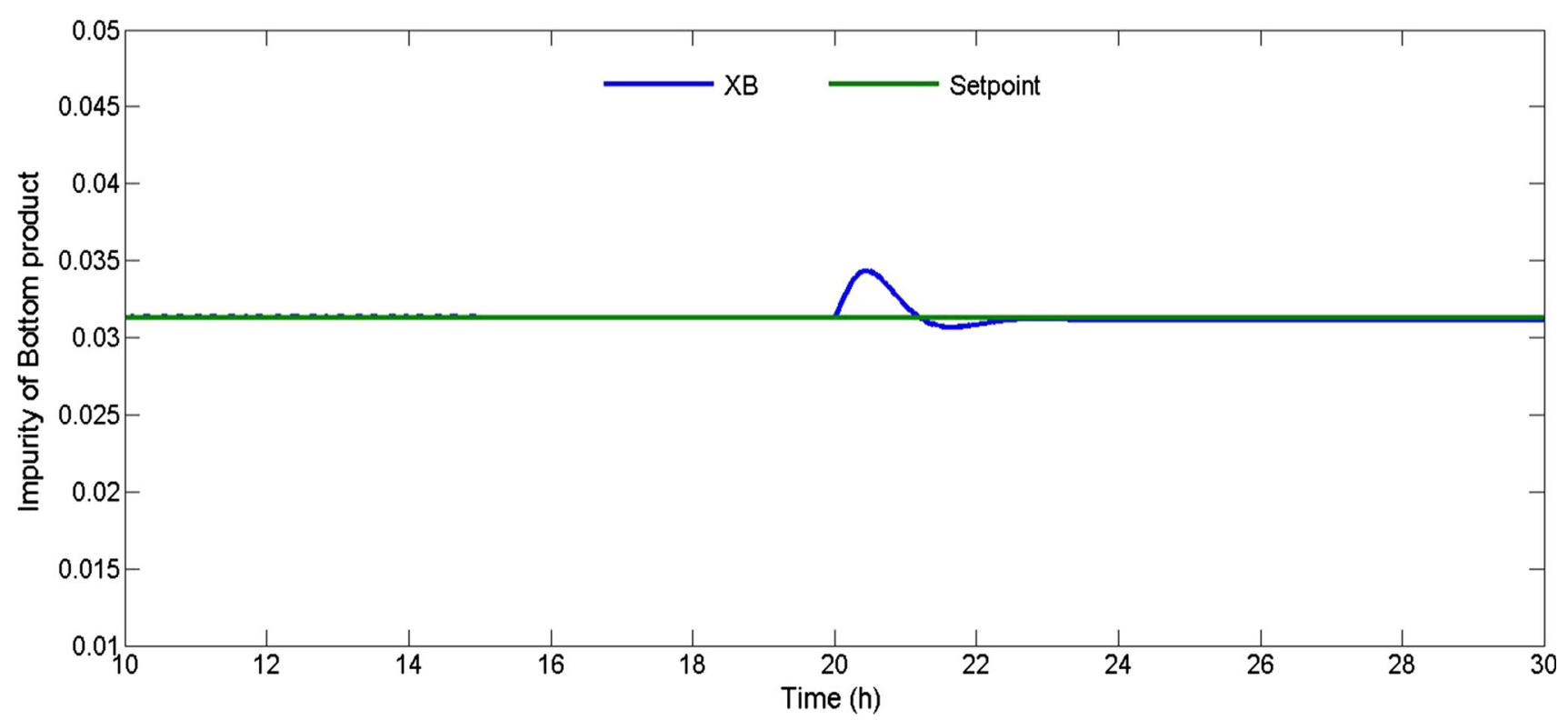

Figure 8. Regulatory response of the simulated model based controller for bottom product quality.

Table 6. PID controller performance comparison of binary distillation column.

\begin{tabular}{|c|c|c|c|c|c|c|c|}
\hline \multirow[b]{2}{*}{ Process } & \multirow[b]{2}{*}{ Compositions } & \multicolumn{3}{|c|}{ PID tuned using full order model } & \multicolumn{3}{|c|}{ PID tuned using reduced order model } \\
\hline & & ISE & IAE & MSE & ISE & IAE & MSE \\
\hline \multirow[t]{2}{*}{ Linear } & $X_{B}$ & 0.4141 & 20.8925 & 0.0836 & 0.3780 & 18.9139 & 0.0757 \\
\hline & $X_{D}$ & 306.13 & 894.06 & 1.0358 & 407.57 & 937.24 & 1.0375 \\
\hline \multirow[t]{2}{*}{ Non-linear } & $X_{B}$ & 44.69 & 24.1392 & 0.0841 & 32.80 & 27.584 & 0.0746 \\
\hline & $X_{D}$ & 206.12 & 985.75 & 1.0422 & 387.65 & 845.42 & 1.0472 \\
\hline
\end{tabular}

inequalities: QP - in MATLAB quadprog function from optimization toolbox. The Hessian matrix $\mathbf{M}$ and gradient vector $\mathbf{m}$ are obtained from Eq. (42). The inequality constraints and lower and upper bounds [31] are given by

$$
\mathbf{A} \mathbf{U} \leq \mathbf{b} ; \mathbf{A}_{e q} \mathbf{U}=\mathbf{b}_{e q} ; \quad \mathbf{l b} \leq \mathbf{U} \leq \mathbf{u b} .
$$

Step by step implementation procedure for constrained GPC with transfer function model is described as follows:

1) Define system continuous time process model and initialize sampling time, constraints, polynomial filter coefficients, weighting coefficient for control error and control increment.

2) Discretize the system transfer function model.

3) Compute prediction matrices $(\mathbf{G}, \mathbf{F})$.

4) Compute $\mathbf{H}, \mathbf{g}$ and other matrices for cost function by quadratic programming. Update $\mathbf{g}$ and $\mathbf{b}$ inside control cycle.

5) MPC iteration, at each time instant $k$ recursively a) compute $y_{1}(k)$ and $y_{2}(k)$ (simulated output or measured output);

b) find prediction error $e_{1}(k)=y_{1}(k)-\hat{y}_{1}(k)$ and $e_{2}(k)=y_{2}(k)-\hat{y}_{2}(k)$;

c) find $\Delta u_{1}$ and $\Delta u_{2}$ from cost function by considering constraints using QP;

d) determine predicted outputs $\hat{y}_{1}(k+1)$ and $\hat{y}_{2}(k+1)$.

\section{Results and discussion}

\subsection{Location of poles}

The pole-zero spectrum of the full order $\left(16^{\text {th }}\right)$ original transfer function is shown in figure 3 . The plant poles are located at $p_{1}=-99.8905, \quad p_{2}=-80.0087$, $p_{3}=-69.7103, \quad p_{4}=-62.3181, \quad p_{5}=-50.1214$, $p_{6}=-42.2187, \quad p_{7}=-34.012, \quad p_{8}=-29.9989$, $p_{9}=-24.4728, \quad p_{10}=-17.9833, \quad p_{11}=-15.0707$, $p_{12}=-10.7188, \quad p_{13}=-7.8889, \quad p_{14}=-5.5823$, 
$p_{15}=-1.5563$ and $p_{16}=-0.4098$. From figure 3 , it is evident that the given original system has all the poles lying on the left side of the $s$-plane and having no conjugate poles. Using the proposed CDPA, the reduced order system poles are calculated as $p_{\mathrm{c} 1}=-0.3996$ and $p_{\mathrm{c} 2}=-1.3040$.

Using CDPA, the cluster centres are efficiently determined based on the dominant pole concept of the characteristic polynomial. However, in CPDA result only one transfer function pole is mentioned because the original and reduced transfer function matrices have a common denominator polynomial representing the characteristic polynomial. Hence a 16th-order full order model is converted to a 2 nd-order reduced model.

It is seen that the poles from $p_{1}$ to $p_{12}$ lie far away from the $s$-plane origin and cause fast response in decaying with less effect on the system characteristics. The constant coefficients of the denominator polynomial used in the various techniques have an important role to play in stability and performance of an LTI system, while the numerator coefficients also have an influence on the system's response to applied inputs [16]. Model-based control schemes are effectively used in industrial applications, namely cement industry, coal mill industry, etc., where accurate model coefficient estimation plays a crucial role in improving the closed loop system performances.

The gain characteristics of full order model are compared to the model equivalent using CDPA as shown in figure 4. In the Bode diagram, solid red and blue lines represent full order and reduced order model, respectively, of a binary distillation column process. It is observed that the essential dynamics of the system lie in the frequency range of 0.001-1 radian/s from the response. The magnitude drops in both the very low and the high-frequency ranges. It is observed that the reference model has good tracking capabilities in each region of operation with multiple stepping reference inputs.

\subsection{PID controller tuning}

Controller tuning is an essential preliminary procedure for almost all the industrial process control systems. Every process has to be controlled, so that the expected response can be obtained. In industries, PID controllers are commonly used as the controllers. Despite the significant developments in advanced process control schemes such as predictive control, internal model control and sliding mode control, PID controllers are still widely used in industrial control applications, because of their structural simplicity, reputation and easy implementation. In this work, tuning of conventional PID controller uses the Ziegler-Nichols closed loop method for controller design. The controller parameters obtained are summarized in table 5 .

Comparative closed loop controller responses of PID controller for linearized full order, linearized reduced order and first-principle model are shown in figure 5. In figure 5, the setpoints for bottom product $X_{B}$ and top product $X_{D}$ are plotted as red solid lines at various time intervals, black dotted and dashed lines are the output responses for linearized reduced order and full order models, respectively, and blue dotted line represents the output responses using the first-principle model. The result obtained shows that the reference is followed satisfactorily but with an overshoot. Output responses of a binary distillation column with PID controller tuned using first-principle model show that both outputs take more settling time to track the setpoints when compared with the responses of linearized reduced order and full order model of a binary distillation column in figure 5.

Table 6 summarizes comparative studies of PID controller performance indices, mainly ISE, IAE and MSE of the binary distillation column. The study shows that the bottom product error values are minimum for linearized reduced order model and top product error values are minimum for linearized full order model when compared with the first-principle model.

PID controller tuned using reduced order model is able to perform on par with PID controller tuned using full order model. The PID controller tuned using reduced order model exhibits good performance for the simulated non-linear process.

\subsection{Analysis of controller}

The linearized and simulated models were analysed for $5 \%$ feed composition variation as a disturbance in a distillation column. The model responses are shown in figure 6 .

The simulation experiment was carried by increasing feed flow rate by $3 \%$ from its nominal value. The responses obtained for the decoupled system with simulated model are shown in figures 7 and 8.

It is observed from figures 7 and 8 that the designed controller is able to reject the disturbance with smaller overshoot and lesser settling time.

\subsection{GPC as a class of MPC}

In this section, the response is obtained for multiple step changes in the reference in a GPC with prediction horizon

Table 7. Generalized Predictive Controller parameters for full order and reduced order binary distillation column.

\begin{tabular}{lc}
\hline Controller parameter & Value \\
\hline Sampling time & $1 \mathrm{~s}$ \\
Start of costing horizon & 1 \\
End of costing horizon & 40 \\
End of control horizon & 40 \\
Weighting coefficient for control error & $1 \times 10^{5}$ \\
Weighting coefficient for control increments & 1 \\
\hline
\end{tabular}


Table 8. MPC performance comparison of full order with reduced order linear and nonlinear model of binary distillation column.

\begin{tabular}{|c|c|c|c|c|c|c|c|}
\hline \multirow[b]{2}{*}{ Process } & & \multicolumn{3}{|c|}{ GPC tuned using full order model } & \multicolumn{3}{|c|}{ GPC tuned using reduced order model } \\
\hline & & ISE & IAE & MSE & ISE & IAE & MSE \\
\hline \multirow[t]{2}{*}{ Linear } & $X_{B}$ & 0.33297 & 9.1201 & 0.0013 & 0.33296 & 9.1209 & 0.0013 \\
\hline & $X_{D}$ & 247.66 & 248.82 & 0.9906 & 247.65 & 248.83 & 0.9906 \\
\hline \multirow[t]{2}{*}{ Simulated non-linear } & $X_{B}$ & 0.33315 & 9.1200 & 0.0013 & 0.33323 & 9.1204 & 0.0013 \\
\hline & $X_{D}$ & 247.65 & 248.83 & 0.9906 & 247.66 & 248.83 & 0.9906 \\
\hline
\end{tabular}
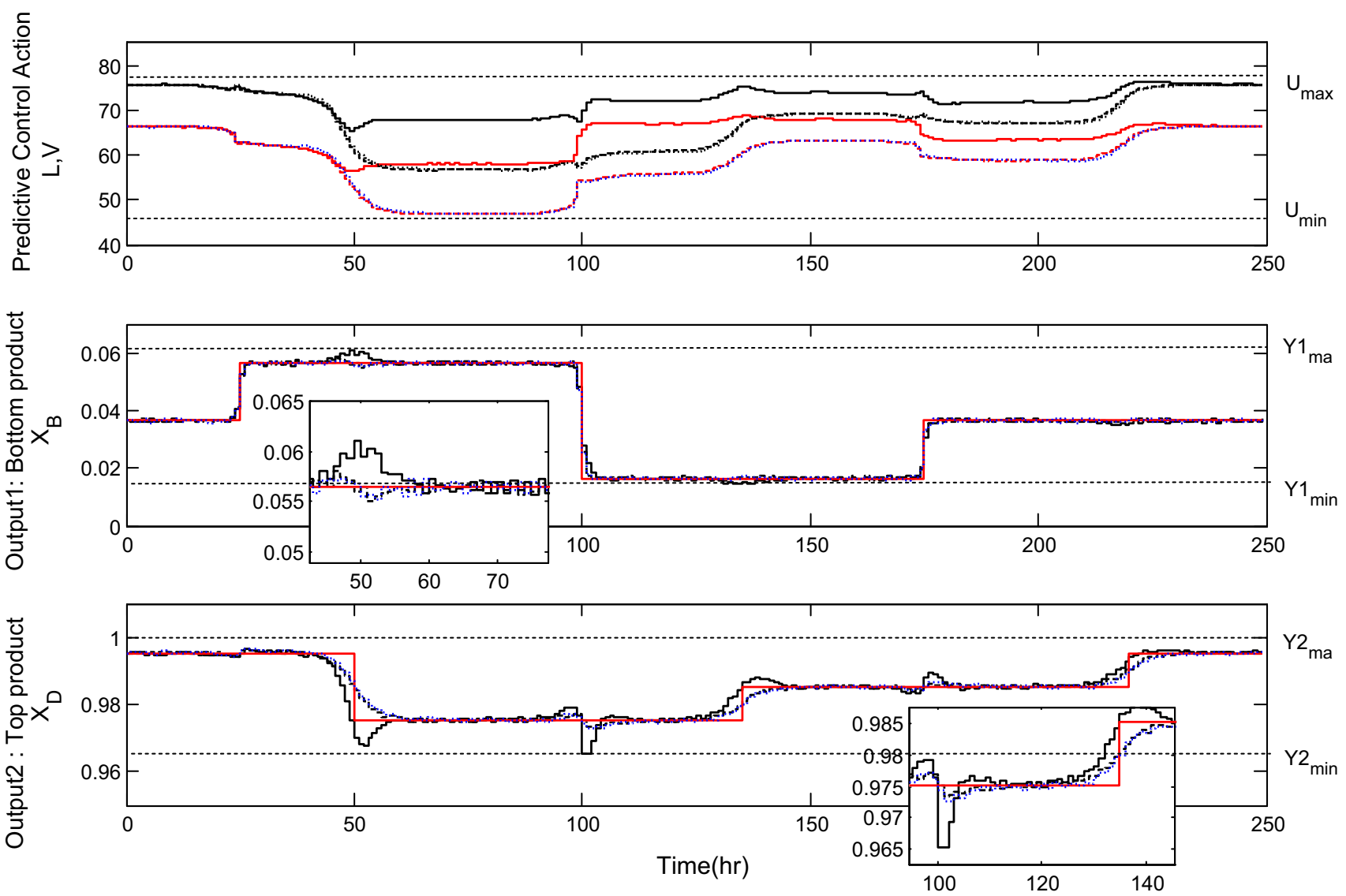

Figure 9. Comparative output responses of binary distillation column with constrained GPC design using various models for (a) predictive control actions, (b) bottom product and (c) top product.

of 40, a control horizon of 40 and weighting factors of $1 \times 10^{5}$ and 1 are applied to the system for control error and control increments, respectively. The controller parameters for full order and reduced order binary distillation column are summarized in table 7 .

Multiple positive and negative set-point steps were applied for bottom product $X_{B}$ (output 1) at time $t=25 \mathrm{~h}$, $175 \mathrm{~h}$ and $t=100 \mathrm{~h}$, respectively. Similarly, multiple positive and negative set-point steps were also applied for top product $X_{D}$ (output 2) at time $t=135 \mathrm{~h}, 220 \mathrm{~h}$ and $t=50 \mathrm{~h}$, respectively.
Figure 9a shows the behaviour of the multivariable process in the presence of changes in $L$ and $V$ with solid black and red lines, which represents the nonlinear modelpredictive controller action, respectively, and remaining lines in the subplot indicate linearized reduced order and full order model-predictive controller actions. It is observed that the output follows the reference by means of the contribution of the two manipulated variables $L$ and $V$. It is also seen that any change affects all the variables with a slight deviation from its reference during the transient stage. 
Table 9. Comparison of time elapsed for full order with reduced order linear and nonlinear model of binary distillation column.

\begin{tabular}{lcc}
\hline & \multicolumn{2}{c}{ Time elapsed (s) } \\
\cline { 2 - 3 } Process & Full order system & Reduced order system \\
\hline Linear & 5.2713 & 4.3387 \\
Simulated non-linear & 5.8200 & 4.5376 \\
\hline
\end{tabular}

Table 10. Comparison of matrix dimensions and memory used for full order to reduced order constrained MPC of binary distillation column.

\begin{tabular}{lccccc}
\hline & \multicolumn{2}{c}{ Full order system } & & \multicolumn{2}{c}{ Reduced order system } \\
\cline { 2 - 3 } \cline { 5 - 6 } Vector & $\begin{array}{c}\text { Matrix } \\
\text { dimension }\end{array}$ & $\begin{array}{c}\text { Memory } \\
\text { (bytes) }\end{array}$ & & $\begin{array}{c}\text { Matrix } \\
\text { dimension }\end{array}$ & $\begin{array}{c}\text { Memory } \\
\text { (bytes) }\end{array}$ \\
\hline $\mathbf{F}$ & $80 \times 132$ & 84480 & & $40 \times 20$ & 12800 \\
$\mathbf{X}$ & $132 \times 1$ & 1056 & & $20 \times 1$ & 160 \\
\hline
\end{tabular}

In figure $9 \mathrm{~b}$ and $\mathrm{c}$, the setpoints for bottom product $X_{B}$ and top product $X_{D}$ are plotted as red solid lines at various time intervals; black and blue dotted lines are the output responses for linearized reduced order and full order models, respectively; solid black line represents the output responses using first-principle model. Output responses of the controller with the transfer function for linear and nonlinear model are shown in figure 9. It is observed that similar and better results are obtained when compared with control response using first-principle model of binary distillation column.

The simulation results of constrained GPC controller with linearized and nonlinear models for the simulated binary distillation column are presented. Satisfactory closed loop responses are obtained for the non-linear process with the controller designed using the linear model.

GPC performance comparisons of full order to reduced order linear and nonlinear models are tabulated in table 8. Studies shows that performance indices with linearized reduced and full order are minimum when compared with first-principle model. The performance indices such as ISE, IAE and MSE are significantly lower in constrained GPC controller for the chosen multivariable binary distillation column. It is also investigated that time elapsed for simulating the reduced order model is lesser for a reduced order model when compared with that of a full order model and is summarised in table 9 .

Table 10 gives a comparative study of matrix dimension and memory utilized for simulation of full order and reduced order constrained GPC of a binary distillation column. The reduced order model requires less memory storage and provides similar dynamics to represent a complex nonlinear process; hence computational complexity is low and it is simple to design a multivariable binary distillation column process.

\section{Conclusions}

A standard predictive control scheme using a model order reduction method based on a new hybrid algorithm has been presented. In the proposed CDPA method, the denominator of the reduced model is obtained using the cluster technique in which the dominant poles are grouped into several clusters and replaced by the corresponding cluster centres. The GPC as a class of MPC employs three different model structures for a binary distillation column, namely (i) linearized full order model, (ii) linearized reduced order model and (iii) nonlinear first-principle model using MATLAB. The output responses of GPC based on the linearized reduced order model match the system dynamics and show characteristics close to that of the linearized full order model. The proposed method can be used for many complex nonlinear multivariable processes. The efficacy of the proposed algorithm is demonstrated with the help of a simulated complex non-linear multivariable binary distillation column process; it is observed that it shows better responses than those from conventional techniques in terms of error minimization for processes with constraints on inputs and outputs. The simulated numerical results show that the proposed method is simple and efficient to compute dominant poles that match the original system properties to give minimum performance indices. Hence, the computational complexity, computer memory and time elapsed for simulation can be reduced using a reduced order model for a distillation column process.

\section{References}

[1] Honc D, Sharma R, Abraham A, Dušek F and Pappa N 2016 Teaching and practicing model predictive control. In: Proceedings of the 11th IFAC Symposium on Advances in Control Education (ACE), Bratislava-Slovakia, IFACPapersOnline 49(6): 34-39

[2] Mahfouf M and Linkens D A 1997 Constrained multivariable generalized predictive control (GPC) for anaesthesia: the quadratic-programming approach (QP). Int. J. Contr. 67(4): 507-528

[3] Wilkinson D J, Morris A J and Tham M T 1994 Multivariable constrained predictive control (with application to high performance distillation). Int. J. Contr. 59: 841-862

[4] Scokaert P O M and Clarke D W 1994 Stabilizing properties of constrained predictive control. Proc. Inst. Electr. Eng. 141: 295-304

[5] Clarke D W, Mohtadi C and Tuffs P S 1987 Generalized predictive control, part I: the basic algorithm. Automatica 23: 137-148 
[6] Clarke D W, Mohtadi C and Tuffs P S 1987 Generalized predictive control, part II: extensions and interpretations. Automatica 23: 149-160

[7] Aguirre L A 1993 Quantitative measure of modal dominance for continuous systems. In: Proceedings of the 32nd Conference on Decision and Control, pp. 2405-2410

[8] Nagar S K and Singh S K 2004 An algorithmic approach for system decomposition and balanced realized model reduction. J. Franklin Inst. 341: 615-630

[9] Martins N, Pinto H J C P and Lima L T G 1992 Efficient methods for finding transfer function zeros of power systems. IEEE Trans. Power Syst. 7(3): 1350-1361

[10] Abraham A, Pappa N, Honc D and Sharma R 2015 A hybrid method for determination of effective poles using Clustering Dominant Pole Algorithm. Int. J. Math. Comput. Nat. Phys. Eng. 7(3): 102-106

[11] Martins N, Lima L T G and Pinto H J C P 1996 Computing dominant poles of power system transfer functions. IEEE Trans. Power Syst. 11(1): 162-170

[12] Minh V T and Pumwa J 2012 Modeling and adaptive control simulation for a distillation column. In: Proceedings of the 2012 UKSim, $14^{\text {th }}$ International Conference on Modelling and Simulation, pp. 61-65

[13] Minh V T and Abdul Rani M 2009 Modelling and control of distillation column in a petroleum process. Math. Probl. Eng. 2009: 404702

[14] Ogunnaike B A and Ray W H 1994 Process dynamics modeling and control. New York: Oxford University Press

[15] Petro Vietnam Gas Company 2009 Condensate processing plant project-process description. Tech. Rep. 82036-02BM-01. Washington, USA: Petro Vietnam

[16] Mittal A K, Prasad R and Sharma S P 2004 Reduction of linear dynamic systems using an error minimization technique. J. Inst. Eng. India 84: 201-206

[17] Rommes J and Martins N 2008 Computing transfer function dominant poles of large second-order dynamical systems. SIAM J. Sci. Comput. 30(4): 2137-2157

[18] Parmar G, Mukherjee S and Prasad R 2007 System reduction using factor division algorithm and eigen spectrum analysis. Int. J. Appl. Math. Model. 31: 2542-2552
[19] Rommes J and Martins N 2006 Efficient computation of transfer function dominant poles using subspace acceleration. IEEE Trans. Power Syst. 21(3): 1218-1226

[20] Antoulas A C and Sorensen D C 2001 Approximation of large-scale dynamical systems: an overview. Int. J. Appl. Math. Comput. Sci. 11(5): 1093-1121

[21] Kumar V and Tiwari J P 2012 Order reducing of linear system using clustering method factor division algorithm. Int. J. Appl. Inf. Syst. 3(5): 1-4

[22] Aguilera-González A, Astorga-Zaragoza C M, Adam-Medina M, Theilliol D, Reyes-Reyes J and García-Beltrán C D 2013 Singular linear parameter-varying observer for composition estimation in a binary distillation column. IET Control Theory Appl. 7(3): 411-422

[23] Mishra R K, Khalkho R and Rajesh Kumar B 2013 Effect of tuning parameters of a model predictive binary distillation column. In: Proceedings of the IEEE International Conference on Emerging Trends in Computing, pp. 660-665

[24] Yang J S 2005 Optimization-based PI/PID control for a binary distillation column. In: Proceedings of the American Control Conference, pp. 3650-3655

[25] Camacho E F 1993 Constrained generalized predictive control. IEEE Trans. Automat. Contr. 38(2): 327-332

[26] Ansarpanahi S, Noor S B M and Marhaban M H 2008 Stability study of model predictive control in presence of undesirable factors. J. Appl. Sci. 8(20): 3683-3689

[27] Holkar K S and Waghmare L M 2010 An overview of model predictive control. Int. J. Contr. Automat. 3(4): 47-63

[28] Abraham A, Pappa N, Shanmugha Priya M and Hexy M 2017 Predictive control design for a MIMO multivariable process using order reduction techniques. Int. J. Model. Simul. 37(4): 199-207

[29] Wayne Bequette B 2012 Process control modeling, design and simulation. India: Prentice Hall

[30] Clarke D W and Scattolini R 1991 Constrained recedinghorizon predictive control. Proc. Inst. Electr. Eng. 138: 347-354

[31] Tsang T T C and Clarke D W 1998 Generalized predictive control with input constraints. Proc. Inst. Electr. Eng. 35(6): $451-460$ 